\title{
FTICR/MS Analysis of Micromeria Fruticosa and Teucrium Polium Growing in Lebanon
}

\author{
Mohamad Al- Hamwi ${ }^{1, *}$, MahaAboul Ela' ${ }^{1}$, Abdalla El-Lakany' ${ }^{1}$, Youssef BAKKOUR ${ }^{2}$, Ziad Mahmoud ${ }^{1}$
}

\section{Mohamad Al- Hamwi ${ }^{1, *}$, MahaAboul Ela', Abdalla El- Lakany', Youssef BAKKOUR ${ }^{2}$, Ziad Mahmoud $^{1}$}

'Beirut Arab University, LEBANON. ${ }^{2}$ Lebanese University, LEBANON.

\section{Correspondence}

Mohamad Al-Hamwi

Beirut Arab University, LEBANON.

E-mail: abumuath_09@hotmail.com

History

- Submission Date: 14-12-2021;

- Review completed: 29-12-2021;

- Accepted Date: 10-01-2022.

DOI : 10.5530/pj.2022.14.16

Article Available online http://www.phcogj.com/v14/i1

Copyright

(C) 2022 Phcogj.Com. This is an openaccess article distributed under the terms of the Creative Commons Attribution 4.0 International license.

\section{ABSTRACT}

Micomeria fruticosa and Teucrium polium are Lamiaceae plants found throughout the Mediterranean, including Lebanon. Aerial parts of both plants were taken from a rocky mountain in Lebanon's Bekaa region and alcoholic extraction and chromatographic separation were performed. Fourier transform ion cyclotron resonance mass spectrometry (FTICR-MS) was used to examine crude extracts of both plants A and $B$, as well as their fractions. The mass spectra of both plants revealed great chemical complexity with a total of 6352 ions (peaks) for crude extract of plant $A$ and 5147 ions (peaks) for extract $B$. The majority of chemicals found in both plants are condensed aromatics, particularly polyphenols which could explain the previously documented anticancer effects of both plants.

Key words: Micromeria, Teucrium chromatographic analysis, FTICR-MS.

\section{INTRODUCTION}

Plants are considered as significant source of natural bioactive substances with a wide range of applications in pharmaceutical, food, and cosmetic industries and have been used in traditional medicine since ancient times. ${ }^{1}$ Herbal medicine is used by 78 percent of the world's population (in Latin America and Asia) and has been shown to have few negative side effects. ${ }^{2}$ However, the use of natural products has several drawbacks, the most significant of which are the limited availability of the compounds and their minute quantities, which is not usually sufficient for commercial extraction. ${ }^{3}$

Plants of family Lamiaceae, such as those in the genera Micomeria and Teucrium, are widely distributed in the Mediterranean region including Lebanon. ${ }^{4,5}$ They have long been used to treat a variety of maladies, including migraines, gastrointestinal disorders, upper respiratory tract infections, and several cardiovascular diseases. ${ }^{6}$ Both Micromeria and Teucrium are reported as an important source of flavonoid, terpenoid, and phenolic substances responsible for the extensive range of medicinal applications for their antioxidant and anticancer effects. ${ }^{6}$

As an essential aspect of genomics research, Metabolomics aims to gain a comprehensive understanding of metabolic networks by analyzing a wide range of known and novel metabolites found in living organisms simultaneously. The first stage of metabolomics was built up to allow for reliable analyses of known metabolites by comparing them to previously identified compounds. The majority of these metabolomics systems were based on mass spectrometry (MS) technologies, which enabled by a mix of diverse ionization processes and a range of separation methods, including Liquid Chromatography, Gas Chromatography, Capillary electrophoresis, and Fourier-transform ion cyclotron resonance MS (FT-ICR/MS) for metabolite identification and quantification, and nuclear magnetic resonance (NMR) spectroscopy for structural elucidation and relative quantification. ${ }^{7}$

When presenting metabolomics data, finding an acceptable visual approach for representing complicated chemical mixtures can be difficult. ${ }^{8}$ FT-ICR/MS for metabolite identification and quantification by plotting the $\mathrm{H}: \mathrm{C}$ ratio versus the O:C ratio for each compound in the mixture. ${ }^{9}$ VK diagrams have traditionally been used to visualize petrochemical mixtures, for example, where compound identities were determined using well-defined GC-MS spectral libraries. ${ }^{8}$ With the introduction of robust and widely accessible highresolution mass spectrometry (HRMS), VK diagrams are becoming more widely used. ${ }^{10,11}$ This is because HRMS data can be used to determine elemental compositions for a large fraction of chemicals in a mixture and the possibility to derive the ratios needed for VK diagram generation. In addition, the plots can demonstrate information about the nature of the chemicals in the mixture. ${ }^{8,11,12}$

VK diagrams offer several advantages compared to other commonly used visualization formats HRMS data, such as 3 Dimension intensity plots, and base peak chromatograms. VK diagrams can provide information about the chemical classes of the compounds present and the number of compounds in a sample more accurately. This data is also independent of any chromatographic method, making this technique particularly useful for comparing data across time, columns, instruments, and/or laboratories. ${ }^{13}$

Researchers Kew and coworkers developed visualization tools-van Krevelen for FTICR MS instrumentation used in conjunction with other highresolution instruments to analyze a particular form of MS data. ${ }^{13}$ Among a variety of MS technologies, FTICR/MS provides the best resolution performance and ultra-high-mass to charge ratio $(\mathrm{m} / \mathrm{z})$ accuracy of each analyte present in a compound mixture, including plant metabolomics that can be identified 
without chromatographic separation stages. ${ }^{7,14}$ These qualities enable the attribution of suspected metabolite formulae purely based on accurate mass, via matching with computed masses for a particular chemical sequence of compounds, in conjunction with metabolomic database search by accurate mass. ${ }^{14}$ To avoid errors caused by referring to previously published hypothetical compound class maps and the use of axes that exclude a large amount of the observed data, the researchers devised a new method. A prompt-driven, open-access package of scripts to generate VK diagrams called Open Van Krevelen which produced an empirically derived density map of where seven classes of metabolites are most likely to be depicted within the diagram space. This method produced a better map with longer axes and more distinct metabolite groups, leading to wider VK diagrams as a metabolomics data visualization tool. ${ }^{13}$ In conclusion, ultrahigh-resolution MS technologies offer accurate molecular weight information, which in turn can be used to predict the elemental compositions (molecular formulas) of metabolites as clues for their structural elucidation. ${ }^{7}$ Previously, ${ }^{6}$ we found that the crude extracts of Micromeria fruticosa and Teucrium polium, as well as some of their fractions, exhibit significant anticancer activity. This activity motivated us to use this advanced technique to investigate the chemical classes and active ingredients in crude extracts of both plants and their fractions that are responsible for these findings.

\section{EXPERIMENTAL PART}

\section{Plant material}

Micromeria fruticosa and Teucrium polium aerial parts were taken in July 2017 from a rocky mountain in the Lebanese Bekaa valley (1300m above sea level) during their full flowering phase. Dr. Ali Chakas a botanist from the Lebanese University, Faculty of Science) authenticated the plants. Both plant samples processed as described before ${ }^{6}$ Chromatographic separation.

As fully described in our previous study, crude extracts of Micromeria fruticosa (extract A) and Toucrium polium (extract B) were separated using column chromatography, followed by chromatographic isolation of their fractions via elution using mixtures of different organic solvents, yielding 22 fractions for A and 43 fractions for B. ${ }^{6}$

\section{Instrument}

Analyses were performed on a SolariXXR instrument with a 9.4 Tactively shielded superconducting magnet and a dynamically harmonized cell (Bruker Daltonics, Bremen, Germany). The mass spectrometer is equipped with a Varian Nano-electrospray online source (Varian Nano ESI ON, Bruker Daltonics, Bremen, Germany). FT-ICR MS has been invented by Pr Alan G. Marshall and Pr Melvin B. Comisarow in 1974. Compared to all the mass spectrometers currently available, FT-ICR MS is the most powerful. They offer mass resolving power and mass accuracy up to 100 times higher than any other commercially available mass spectrometry technique. Alternatively, viewed only as a separation device, ultra-high-resolution FT-ICR MS offers more than 100 times higher peak capacity than the most effective wet chemical separation methods, making it possible to analyze complex mixtures with no prior chromatography. The only characteristic for better mass spectrometers may be found in the scanning speed $(100 \mathrm{~Hz}$ versus $10 \mathrm{~Hz}$ for the FTICR MS at 100,000 resolutions).

\section{ANALYSIS}

\section{Method}

For all experiment parts of the total extract of both plants and their separated fractions, FT-ICR mass spectra were acquired in positive ion mode. Samples were diluted in acetonitrile $(10 \mathrm{mg} / \mathrm{mL})$. The obtained solutions were further diluted to $100 \mathrm{ng} / \mu \mathrm{L}$ in acetonitrile. Mixture solutions of sample and formic acid at a ratio of 10:1 (sample/formic acid, v/v) were introduced in the spectrometer by direct infusion using a Cole-Parmer single-syringe infusion pump (Cole-Parmer ${ }^{\circledast}$, Vernon Hills, USA) at a rate of $10 \mu \mathrm{L} / \mathrm{min}$ through a $250 \mu \mathrm{L}$ Hamilton syringe (51 mm, Gastight). The syringe is connected to a capillary line (100 $\mu \mathrm{m}$ ID, $360 \mu \mathrm{m}$ OD) equipped with a SilicaTipTM needle $(10 \pm 1 \mu \mathrm{m}$, PicoTipTM Emitter, New Objective, Woburn, MA, USA) to which a potential of $1.3 \mathrm{kV}$ was applied. The front and back trapping potentials were set at $1.5 \mathrm{~V}$ with a skimmer 1 voltage at $20 \mathrm{~V}$. Spectra were acquired using broadband detection, $8 \mathrm{M}$ data points, 300 scans accumulation for a better signal-to-noise ratio with a mass range between $\mathrm{m} / \mathrm{z} 144$ to 1500 . The transient time consisted of $4.20 \mathrm{~s}$, resulting in a resolution of $1,000,000$ at $\mathrm{m} / \mathrm{z} 400$ in the magnitude mode. Ions were accumulated in the hex pole during $0.05 \mathrm{~s}$. Instrument calibration was achieved using an external calibrant (Sodium trifluoroacetate TFA, $0.01 \mathrm{mg} / \mathrm{mL}$ in $\mathrm{H} 2 \mathrm{O} /$ $\mathrm{MeOH} 50 / 50 \mathrm{v} / \mathrm{v}$ ) with a linear calibration. Following the acquisition, spectra were internally calibrated in the Data Analysis software version 5.0 (Bruker Daltonics, Bremen, Germany) using a calibration list of assigned signals limiting the mass error to under $100 \mathrm{ppb}$. Mass spectra treatment was done using a modified python script originating from the FTMS Visualization software (also known as i-van Krevelen) in which masse to formula assignment is based on the Kendrick mass defect and $\mathrm{z}^{\star}$ approach formulae assignment. The attributed compounds were classed according to the number of $\mathrm{CH}_{2}$, instauration, and oxygen atoms in the molecule. Van Krevelen diagrams were generated, and the corresponding families of molecules present in each sample were identified relying on the empirically derived van Krevelen metabolite map. Map displays the areas of highest point density for seven major classes of metabolites: lipids, terpenes, polyketides, monosaccharides, nucleotides, flavonoids, amino acids, and peptides (Figure 1). The $\mathrm{x}$-axis represents the oxygen to carbon ratio, and the y-axis the hydrogen to carbon ratio. Overlap between groups results from the parameters used by the software but more fundamentally arises from the fact that it is not simply the molecular formula of a molecule that dictates its classification but its structure. As molecules with different structures can have similar or even identical molecular formulas, compound classes overlap.

\section{RESULTS AND DISCUSSION}

Analysis of the metabolic profiles of both plants and their fractions identified a total of 6352 ions (peaks) of the whole extract of Micromeria fruticosa (Extract A) (Figure 2) in the positively ionized mode. Metabolite formulas were assigned to the detected masses to provide insight into metabolite diversity and elemental ratios. The $\mathrm{H} / \mathrm{C}$ ratio was plotted against the $\mathrm{O} / \mathrm{C}$ ratio in the Van Krevelen plot (Figure 3).

The mass spectrum of sample A showed high chemical complexity. Van Krevlen plots revealed the presence of high concentrations of aromatics as well as the presence of some lipids. The highest density of formulas contains atomic $\mathrm{H} / \mathrm{C}$ ratios in extract A between 1 and 1.5. This high ratio reflects the absence of highly saturated molecules and also indicates the presence of compounds with short carbon chains. The low $\mathrm{O} / \mathrm{C}$ ratios between 0.4 and 0.6 (Figure 3) show the absence of highly oxygenated compounds. This vicinity corresponds particularly to linear hydrocarbons and condensed aromatics mainly polyphenols which is probably accountable for its significant anticancer effect confirmed in our previous study against MCF7 and A549 cancer cell with $\mathrm{IC}_{50} 28.52$ and $26.47 \mu \mathrm{g} / \mathrm{ml}$ respectively. Many phenolic compounds, predominantly flavonol compounds, epicatechin derivatives of molecular formula $\mathrm{C}_{23} \mathrm{H}_{26} \mathrm{O}_{8}$ (Figures 6 and 7), and eriodicthiol derivatives of molecular formula $\mathrm{C}_{18} \mathrm{H}_{16} \mathrm{O}_{8}$ (Figures 8 and 9) have been identified in fractions $\mathrm{A} 1$ and $\mathrm{A} 4$. Flavone compound of molecular formula $\left(\mathrm{C}_{33} \mathrm{H}_{36} \mathrm{O}_{11}\right)$ in fraction A6 (Figures 10 and 11), flavonoid taxicatigenin derivatives of molecular formula $\mathrm{C}_{18} \mathrm{H}_{20} \mathrm{O}_{4}$ of fraction A8 (Figures 12 and 13), in addition to the identification of two other phenolic compounds of chemical formulae $\mathrm{C}_{26} \mathrm{H}_{42} \mathrm{O}_{8}$ (Figure 14), 

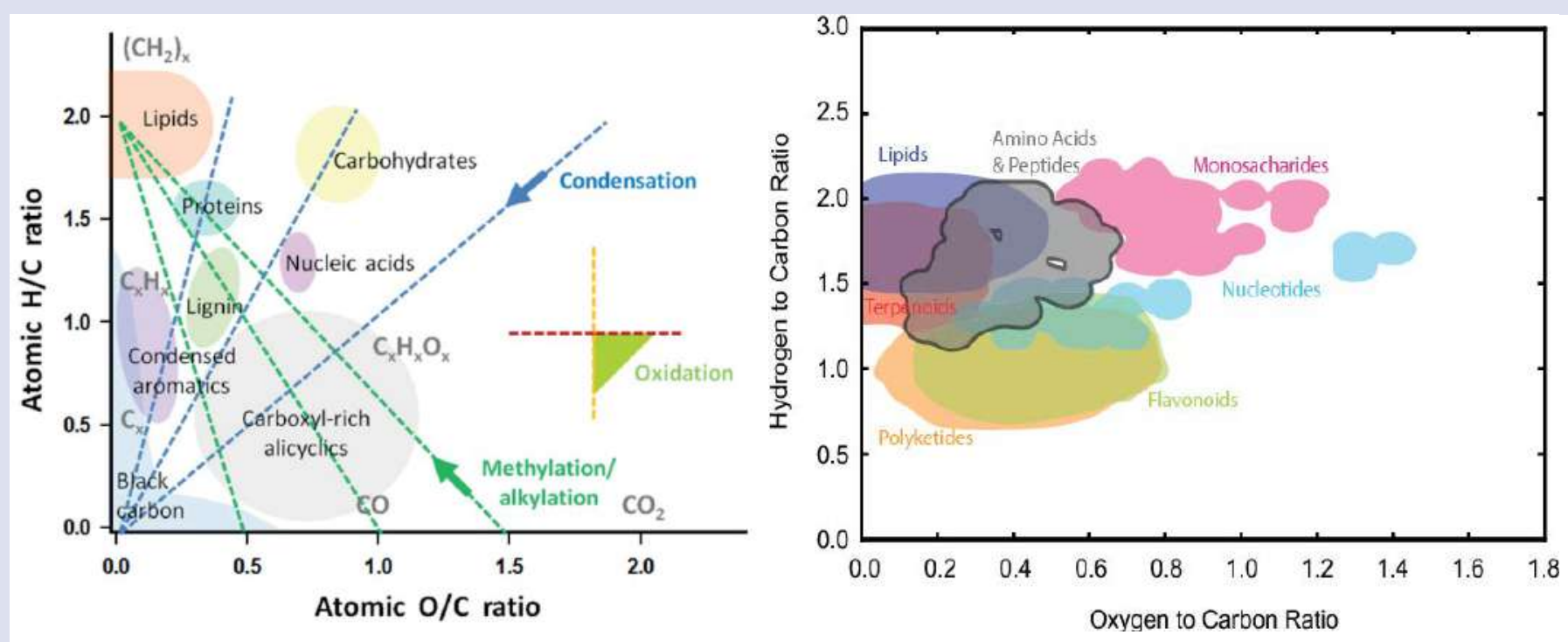

Figure 1: Empirically derived van Krevelen metabolite map.

$\mathrm{A}_{1}-\mathrm{A}_{4-}$

A

6-ethyl-3,5,7-trihydroxy-8-propyl-2-(2,4,5-trihydroxy-3-propylphenyl)chroman-4-one 2-(3,4-dihydroxy-5-methoxyphenyl)-5,7-dihydroxy-3,6-dimethoxychroman-4-one
$\mathrm{A}_{6-}$<smiles>CCCc1c(O)c(O)cc(C2Oc3c(CCC)c(O)c(CC)c(O)c3C(=O)C2O)c1O</smiles>

B<smiles>COc1cc(C2Oc3cc(O)c(OC)c(O)c3C(=O)C2OC)cc(O)c1O</smiles>

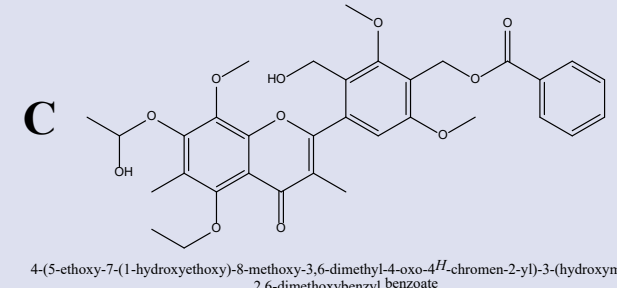

2,6-dimethoxybenzyl benzoate
$\mathrm{A}_{8}-\mathrm{A}_{11-}$<smiles>COc1cc(O)c(C2CC(C)c3ccccc3O2)c(OC)c1</smiles><smiles>CC1[C@@H](C)CCC2C3CCC(C)(C(=O)COC4CC(C[18F])[C@@H](C)[C@H](C)[C@H]4C)C=C3CCC2C1(C)C</smiles>

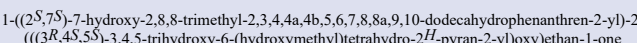

Figure 2: Chemical structures of compounds identified in Micromeria fruticoca.

and $\mathrm{C}_{24} \mathrm{H}_{18} \mathrm{O}_{3}$ (Figures 16 and 17) in fractions A11 and $\mathrm{A} 15$ respectively, these two compounds, besides being unsaturated, their richness in carboxylic and hydroxylic groups that possess antioxidant features, may stand behind their anticancer activity that has been demonstrated in our previous study. ${ }^{6}$

On the other hand, 5147 ions (peaks) were identified in the positive ionization mode for the total extract of Teucrium polium plant (extract B) (Figures 17 and 18). Also, the mass spectroscopy of sample B showed high chemical complexity. The highest density formula contains H/C ratios between 1.5 and 2 . This high ratio reflects the absence of highly saturated molecules and also indicates the presence of compounds with short carbon chains, while the low $\mathrm{O} / \mathrm{C}$ ratios between 0 and 0.5 demonstrate the absence of highly oxygenated compounds and represent the area of lipids and terpenoids (Figure 18). The compound database revealed that the lipid class was the most prevalent within the major metabolic classes, accounting for $73 \%$ of the total detected metabolome. The Van Krevelen plot of elemental data, calculated from the ultra-high resolution mass spectrum (FTICR) for the different fractions of extract $\mathrm{B}$, provides a qualitative visual description of the nature of many compounds and their chemical formulas. Mainly the flavanone, chrome-4-one derivative of chemical formula $\mathrm{C}_{24} \mathrm{H}_{18} \mathrm{O}_{3}$ in 
$\begin{array}{llll}\mathrm{B}_{1} & \mathrm{~B}_{2} & \mathrm{~B}_{3}\end{array}$

A

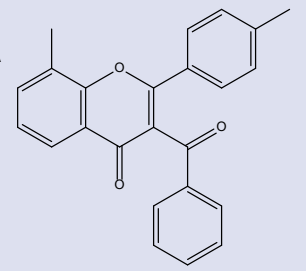

$\mathrm{B}_{4} \mathrm{~B}_{6}$

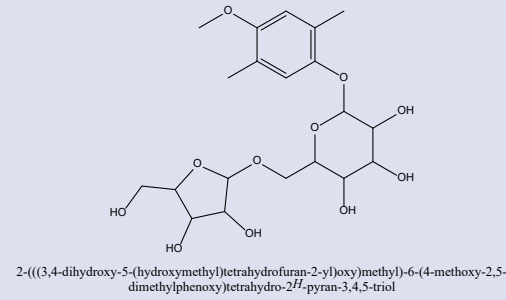

D
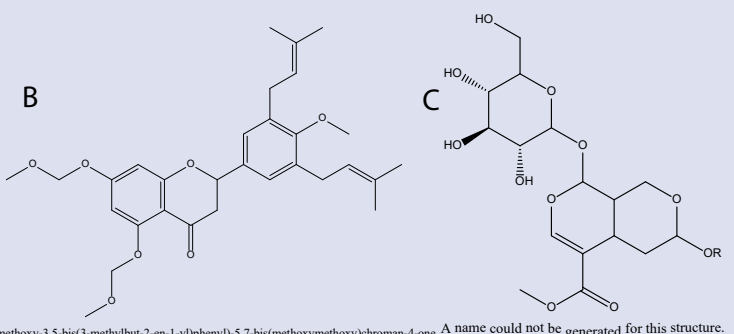

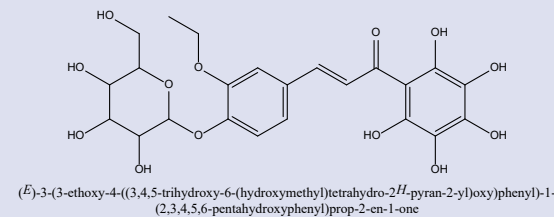

E

Figure 3: Chemical structures of compounds identified in Teucrium polium.
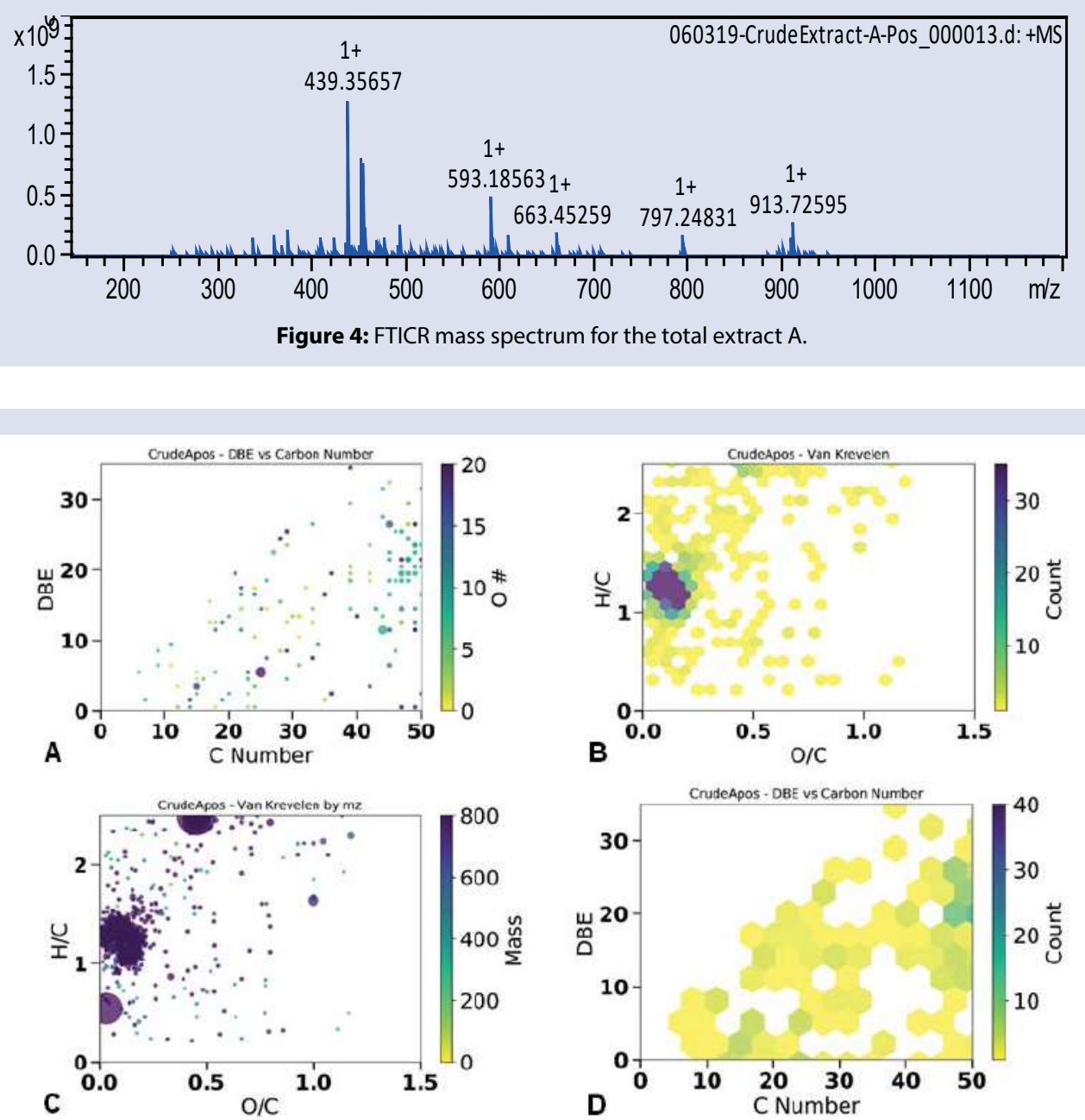

Figure 5: Van Krevelen plot for elemental data calculated from the ultrahigh resolution mass spectrum (FTICR) for the total extract $\mathrm{A}$. 


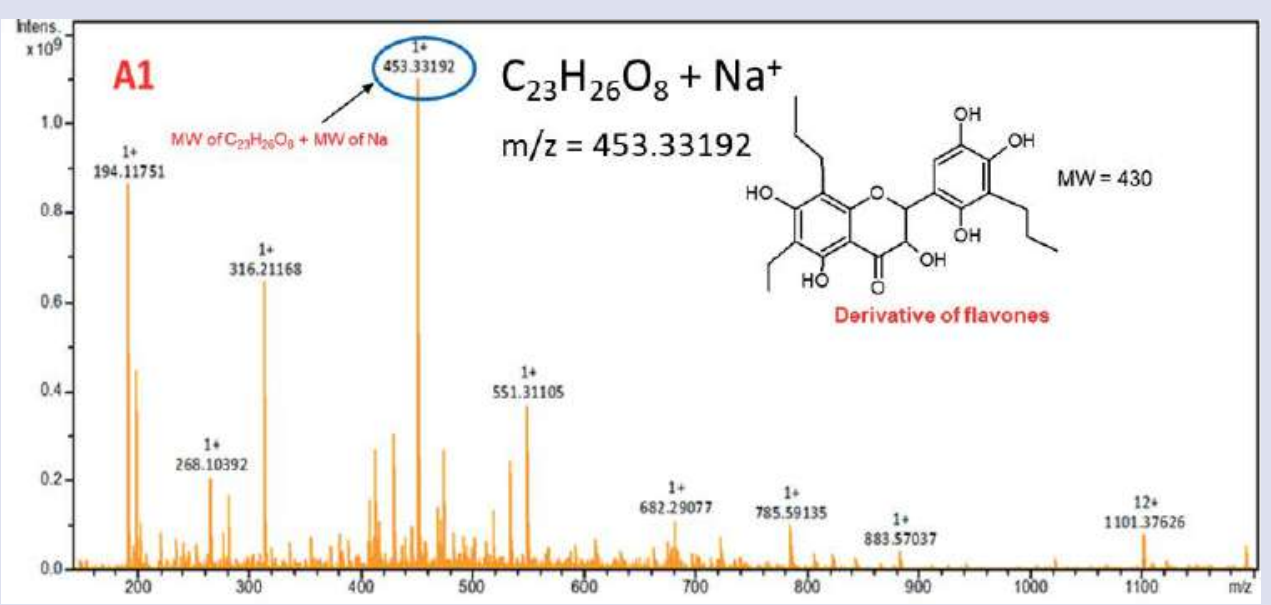

Figure 6: FTICR mass spectrum for the compound A1:Flavanonol (3= Hydroxyflavone). $\mathrm{C}_{23} \mathrm{H}_{26} \mathrm{O}_{8}$ (6-ethyl-3,5,7trihydroxy-8-propyl-2-(2,4,5-trihydroxy-3 propylphenyl)chroman-4-one). Epicatechin derivative.
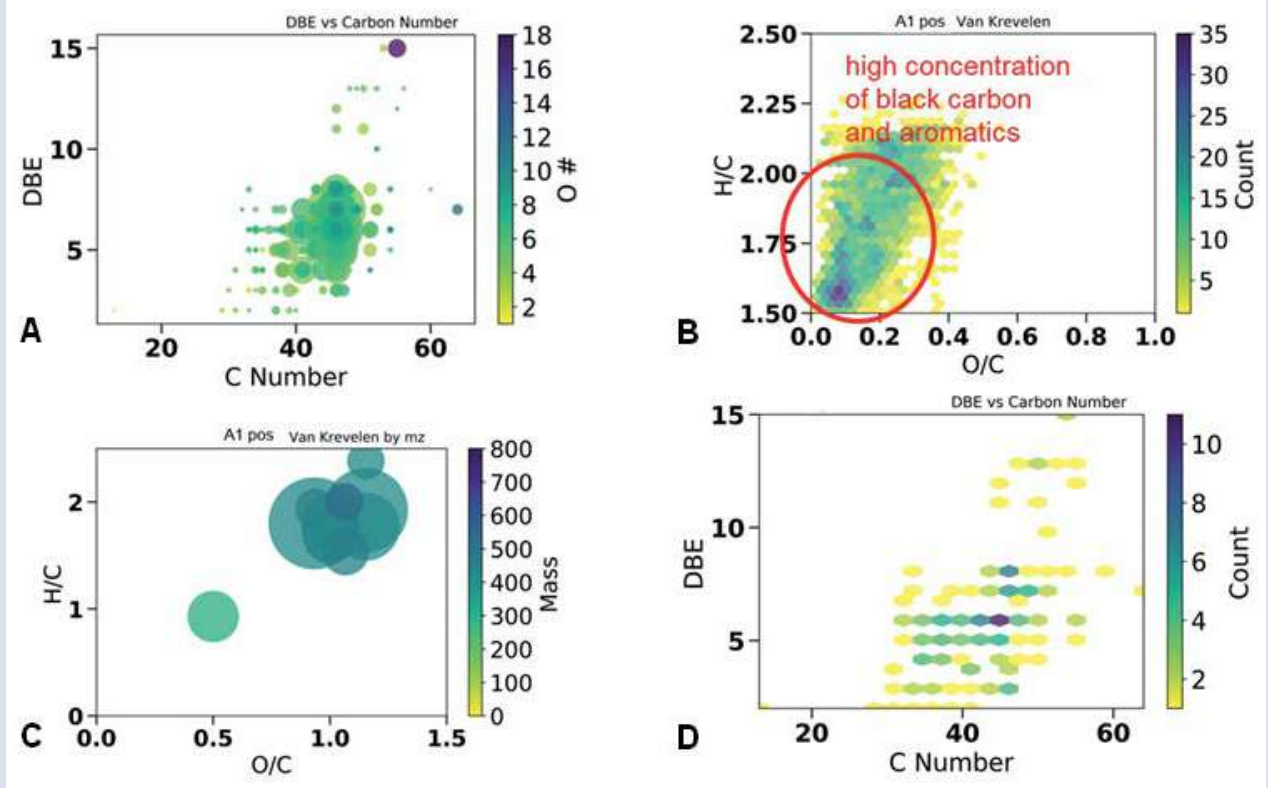

Figure 7: Van Krevelen plot for elemental data calculated from the ultrahigh resolution mass spectrum (FTICR) for the sample named $\mathrm{A} 1 ; \mathrm{C}_{23} \mathrm{H}_{26} \mathrm{O}_{8}$.

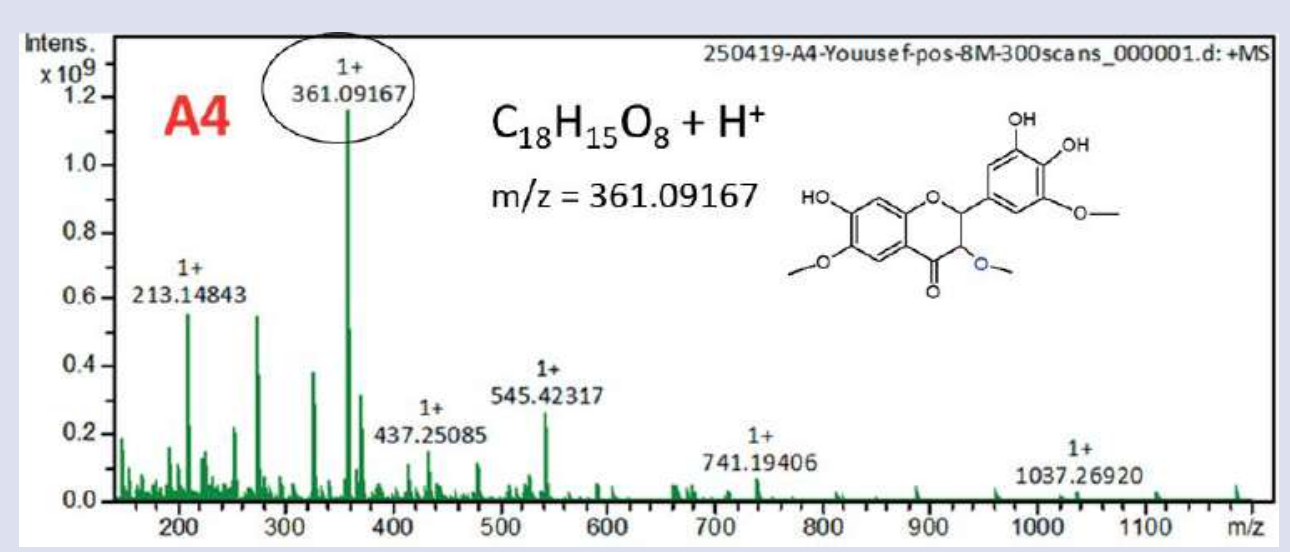

Figure 8: FTICR mass spectrum for the compound $\mathrm{C}_{18} \mathrm{H}_{16} \mathrm{O}_{8}$. From sample A4.2-(3,4-dihydroxy-5-methoxyphenyl)-7hydroxy-3,6-dimethoxychroman-4-one. Derivative of Flavanonols (dihydroquercitin). 


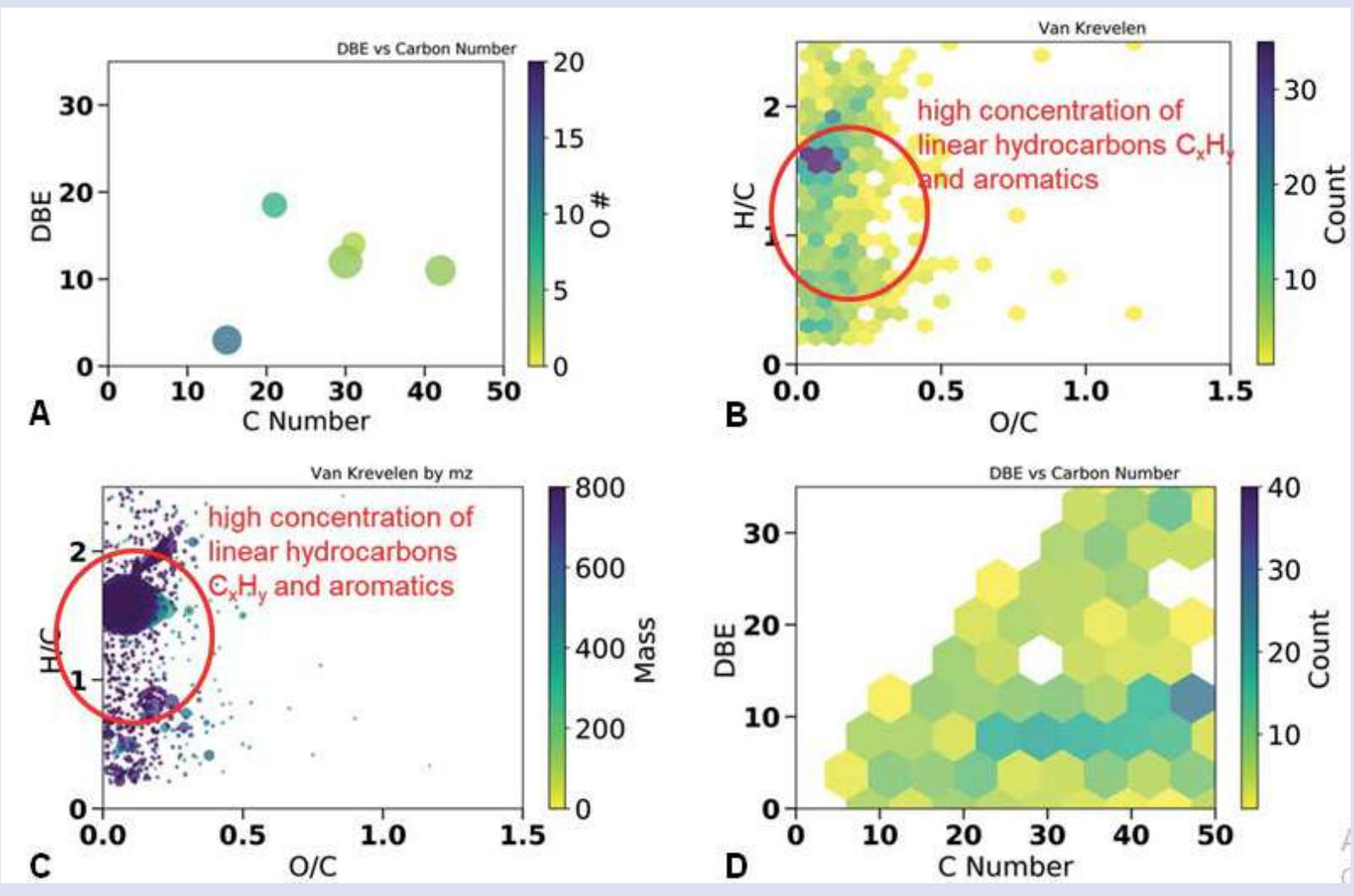

Figure 9: Van Krevelen plot for elemental data calculated from the ultrahigh resolution mass spectrum (FTICR) for the sample named A4.

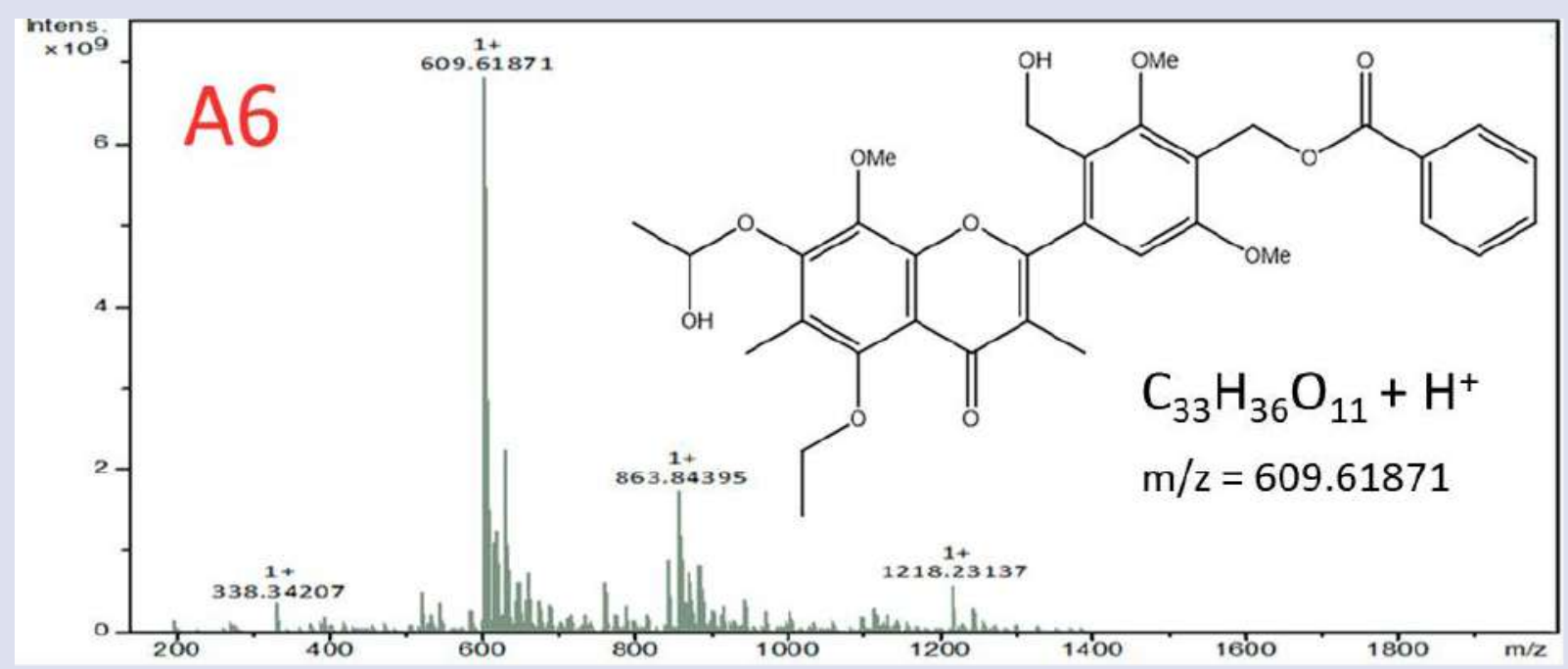

Figure 10: FTICR mass spectrum for the compound $\mathrm{C}_{33} \mathrm{H}_{36} \mathrm{O}_{11}$. From sample named A6. :4-(5-ethoxy-7-(1-hydroxyethoxy)-8-methoxy-3,6-dimethyl-4-oxo4H-chromen-2-yl)-3-(hydroxymethyl)-2,6-dimethoxybenzyl benzoate. 7-methylsudachitin derivative. 

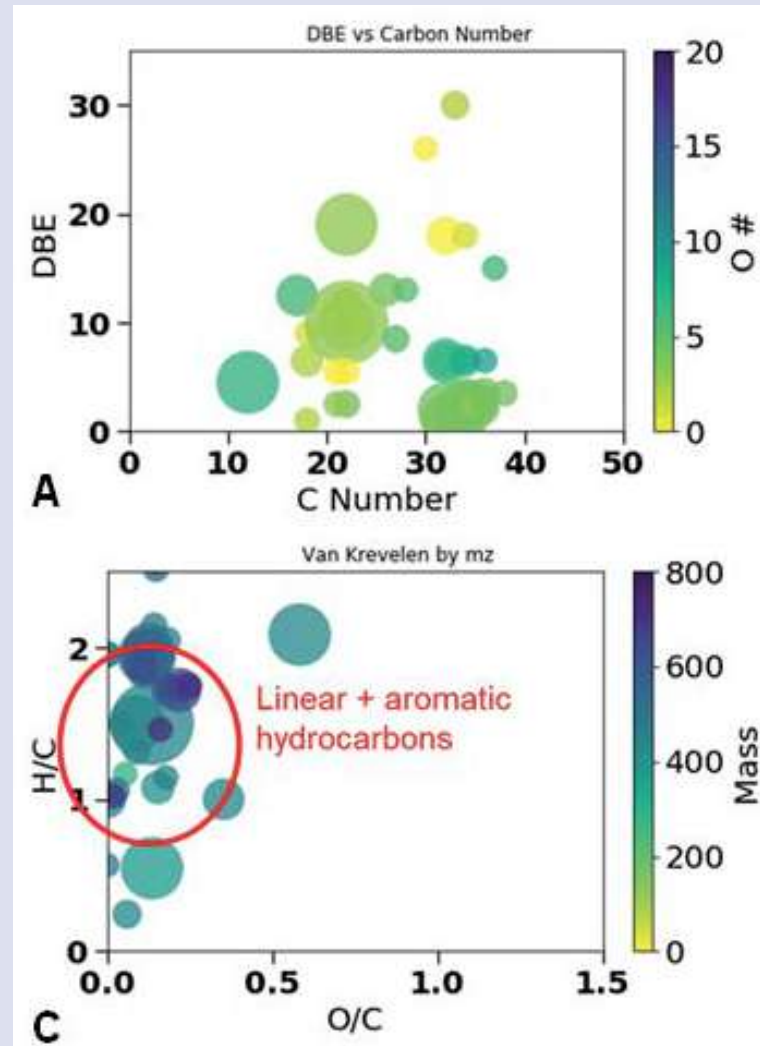
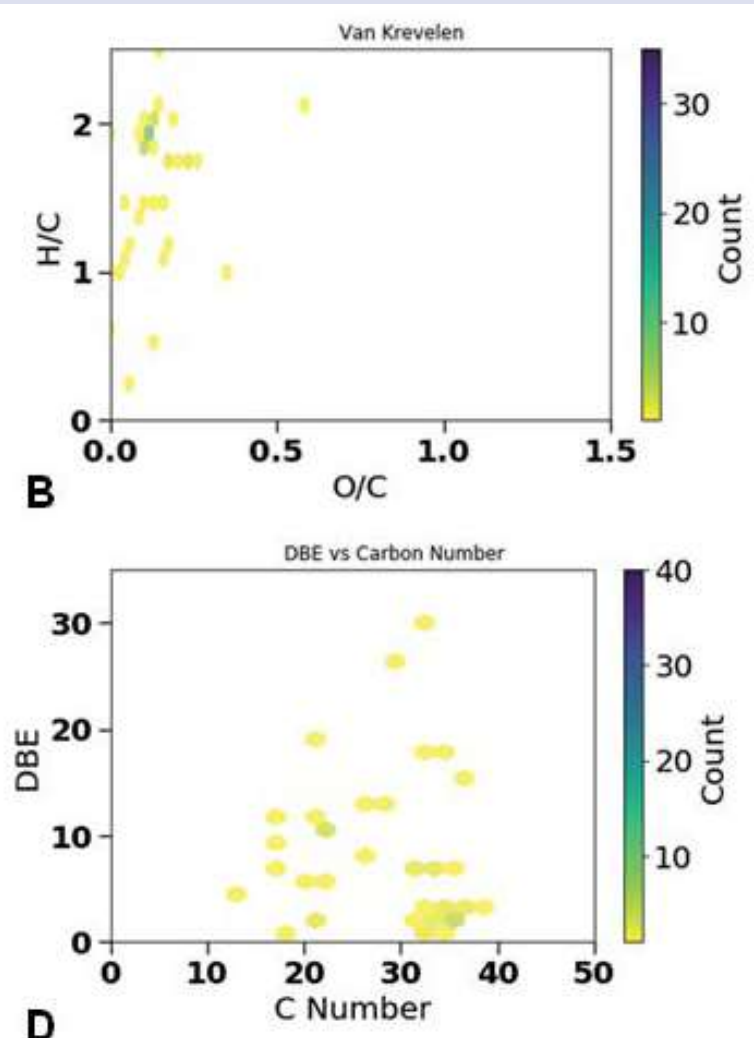

Figure 11: Van Krevelen plot for elemental data calculated from the ultrahigh resolution mass spectrum (FTICR) for the sample named A6.

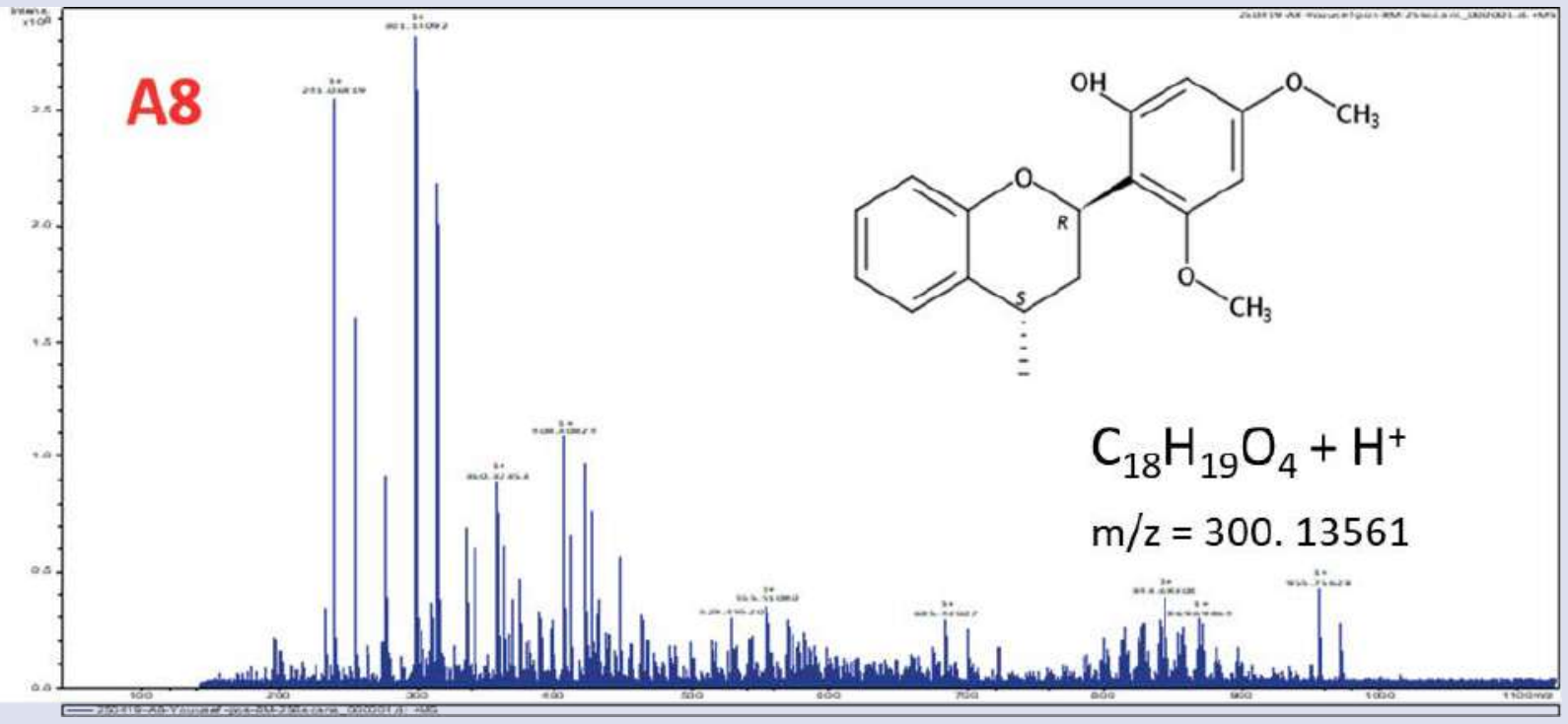

Figure 12: FTICR mass spectrum for the compound $\mathrm{C}_{18} \mathrm{H}_{20} \mathrm{O}_{4}$. From sample named A8. 3,5-dimethoxy-2-((2R,4S)-4-methylchroman-2-yl)phenol. 


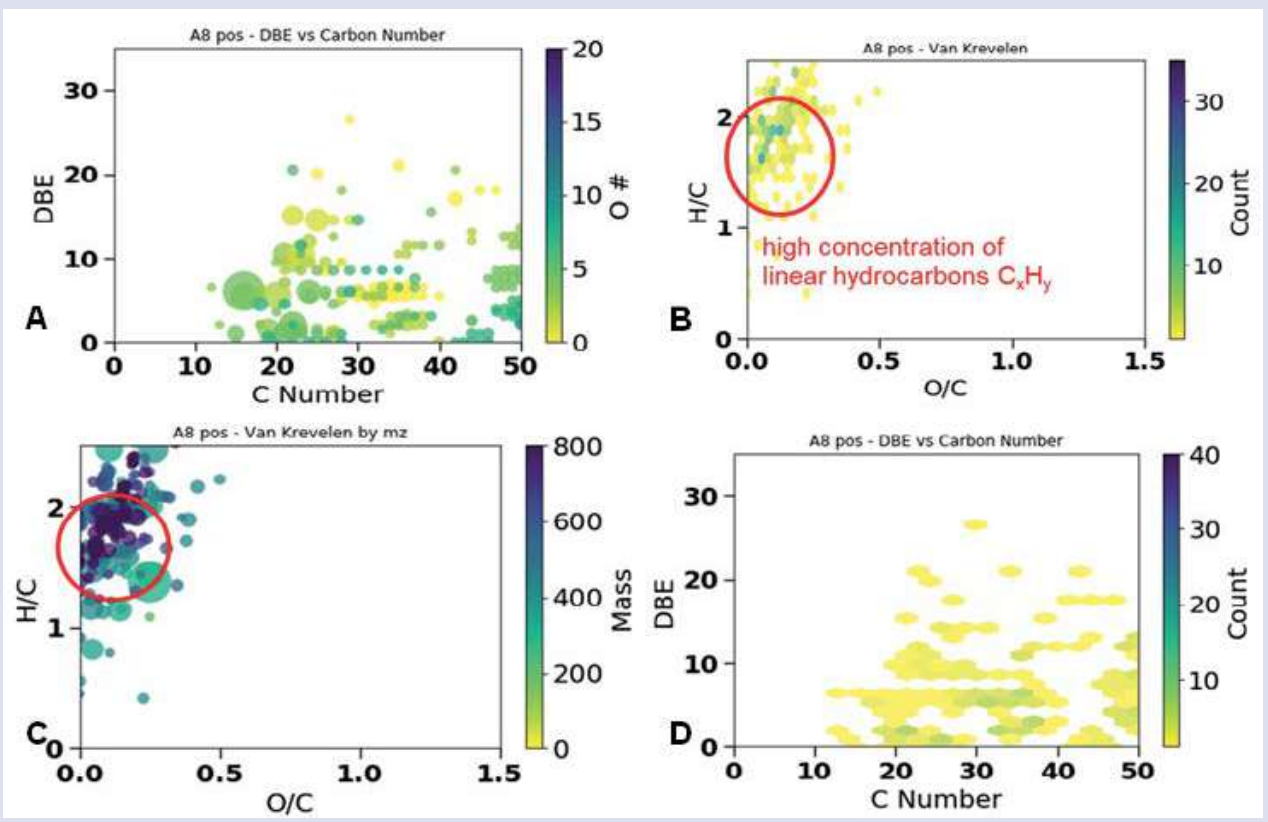

Figure 13: Van Krevelen plot for elemental data calculated from the ultrahigh resolution mass spectrum (FTICR) for the sample named A8.

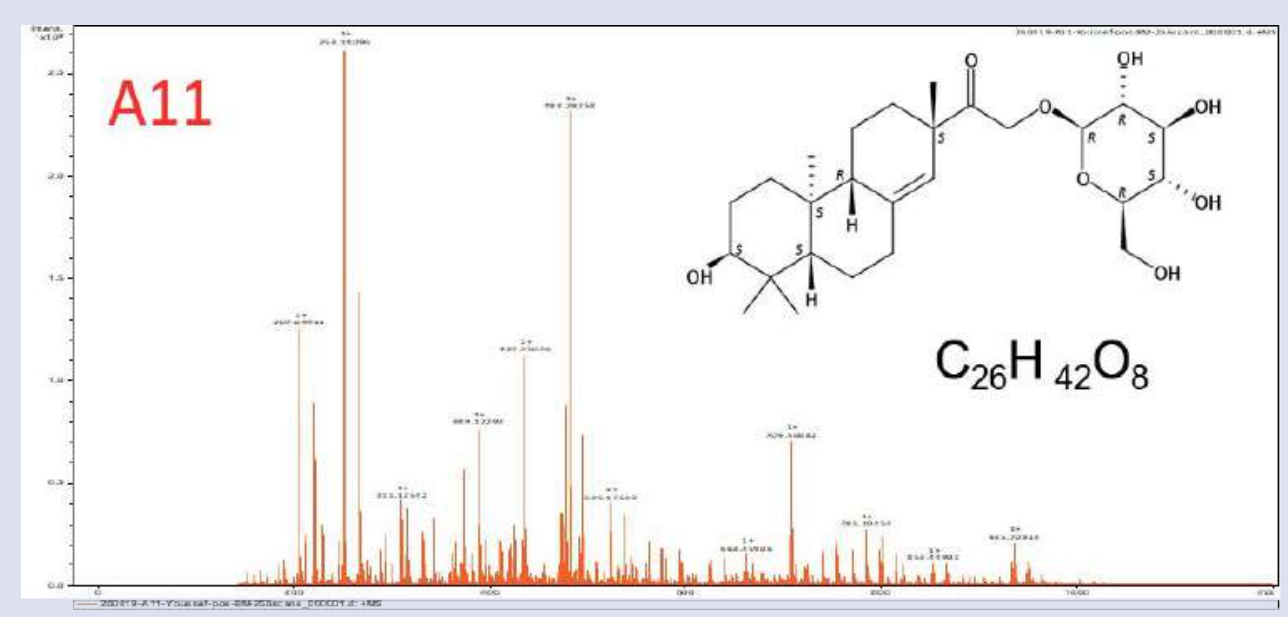

Figure 14: $\mathrm{FTICR}$ mass spectrum for the compound $\mathrm{C}_{26} \mathrm{H}_{42} \mathrm{O}_{8}$. From sample named $\mathrm{A} 11$. phenolic acid derivative.

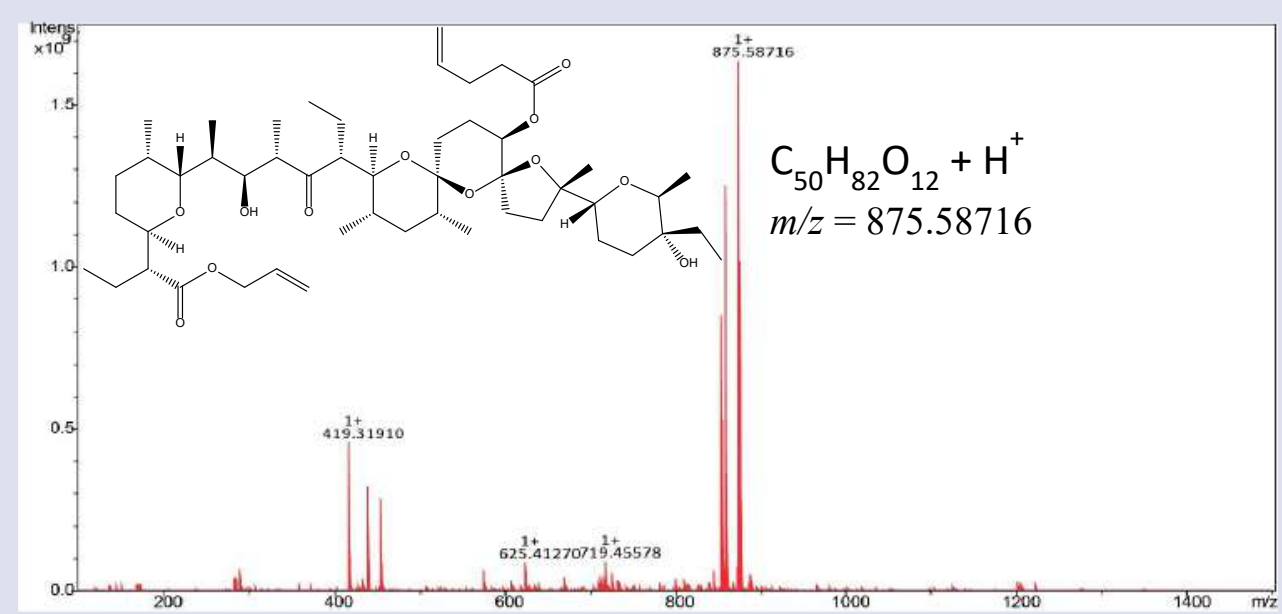

Figure 15: FTICR mass spectrum for the compound $\mathrm{C}_{50} \mathrm{H}_{82} \mathrm{O}_{12}$. From sample named $\mathrm{A} 15$. 


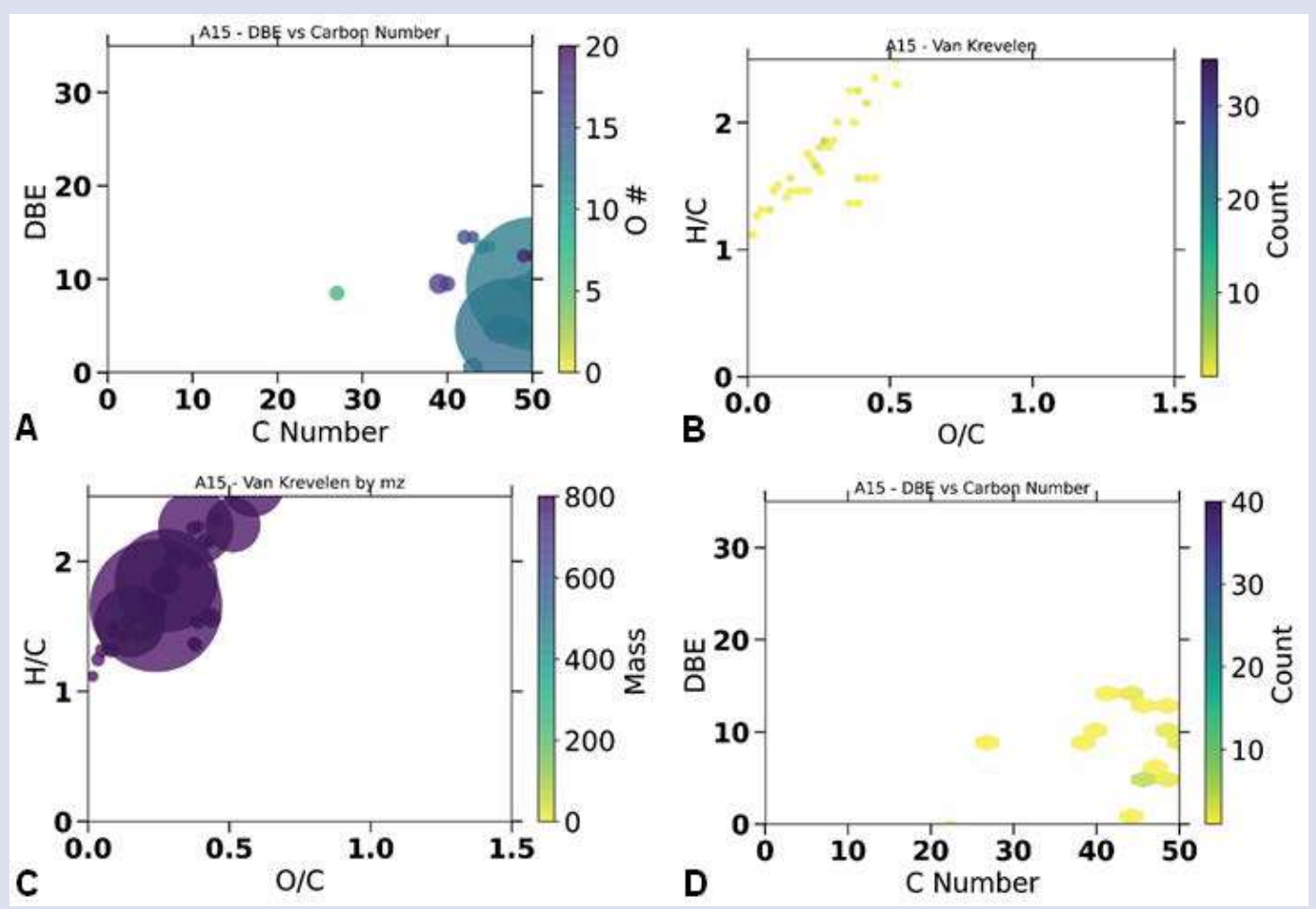

Figure 16: Van Krevelen plot for elemental data calculated from the ultrahigh resolution mass spectrum (FTICR) for the sample named A15.

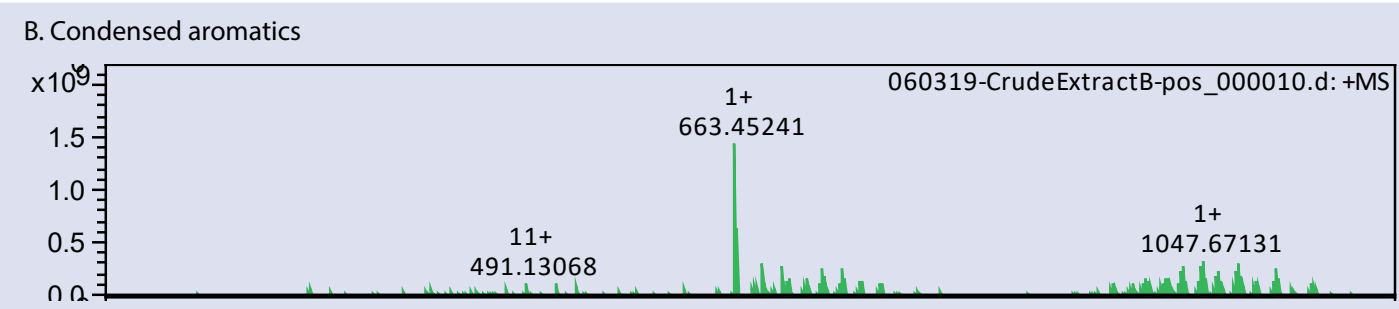

Figure 17: FTICR mass spectrum for the tolat extract $B$.
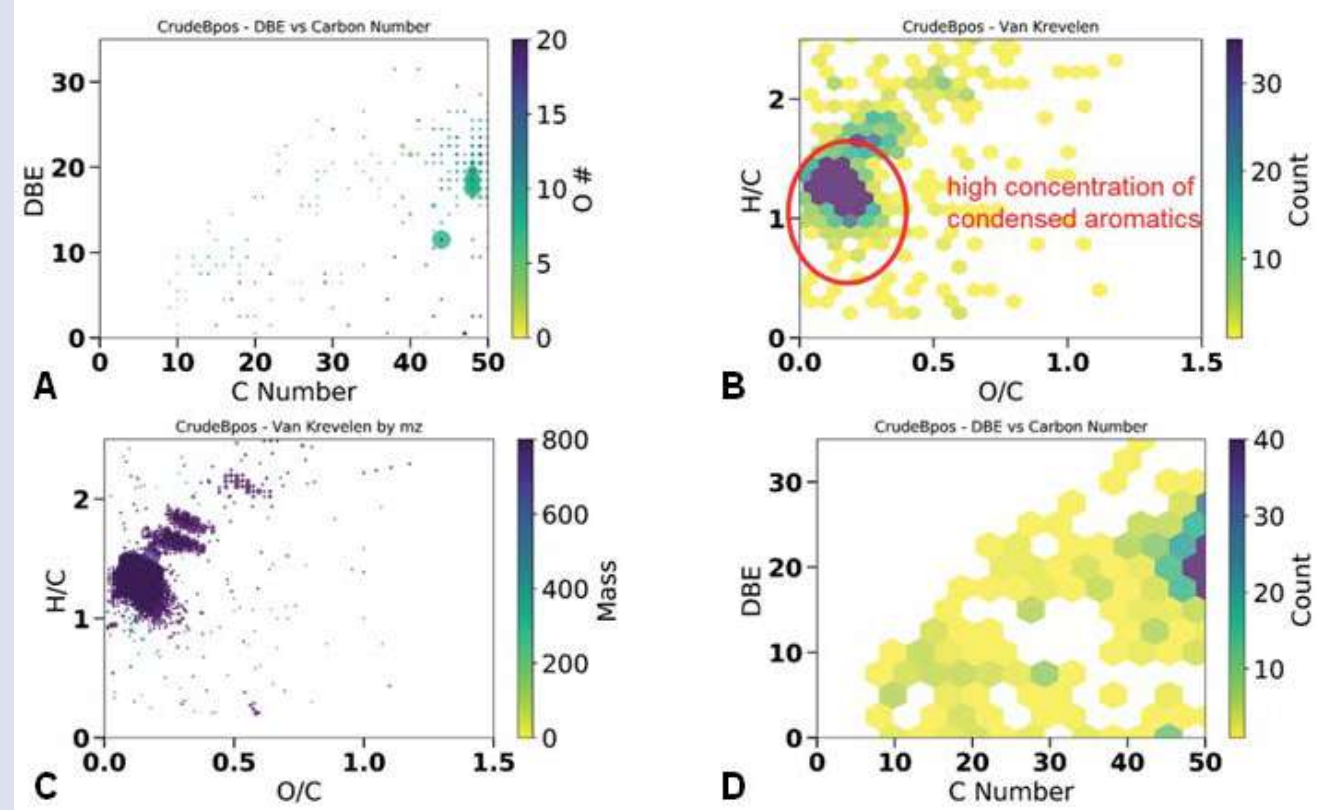

Figure 18: Van Krevelen plot for elemental data calculated from the ultrahigh resolution mass spectrum (FTICR) for the total extract B. 


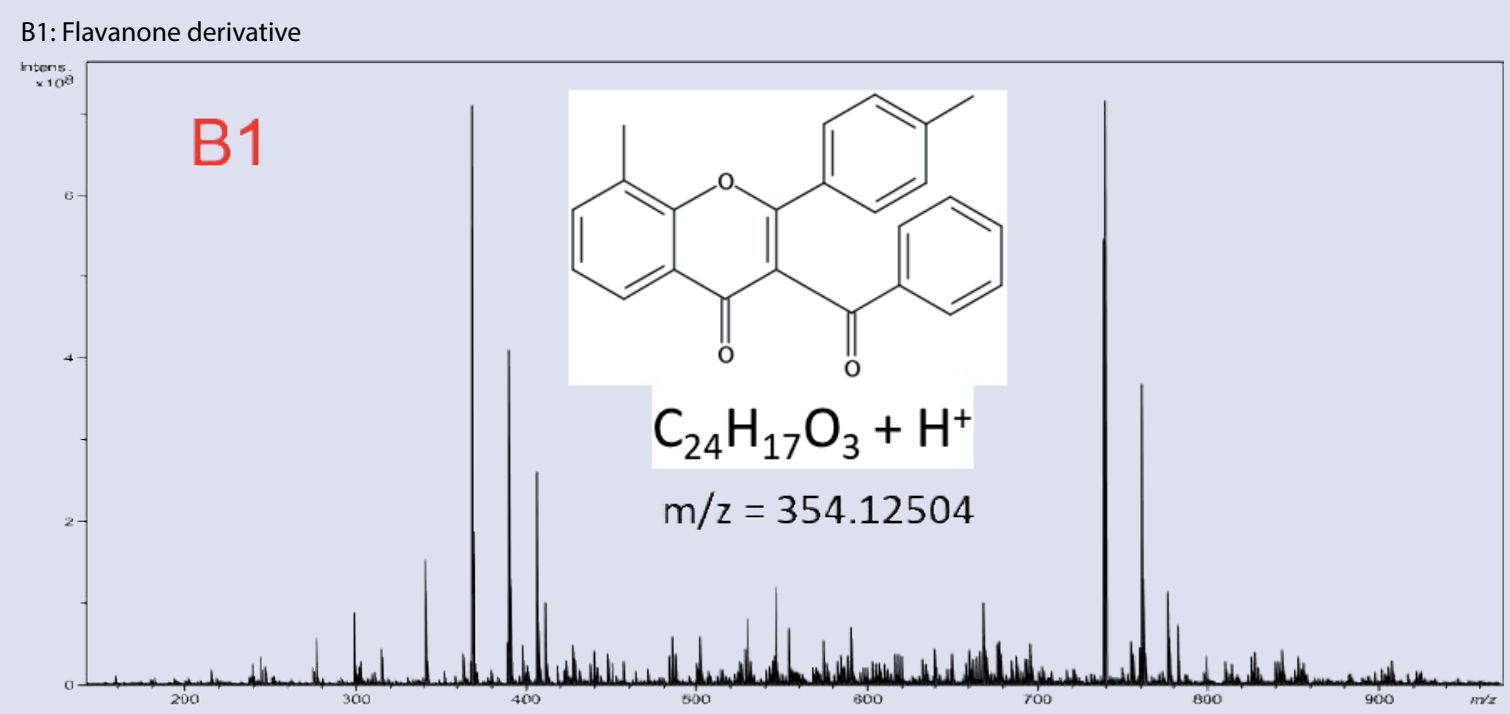

Figure 19: FTICR mass spectrum for the compound $\mathrm{C}_{24} \mathrm{H}_{18} \mathrm{O}_{3}$. From sample named B1. 3-benzoyl-8-methyl-2-(p-tolyl)-4H-chromen-4-one. methyl-2-(ptolyl)-4H-chromen-4-one.
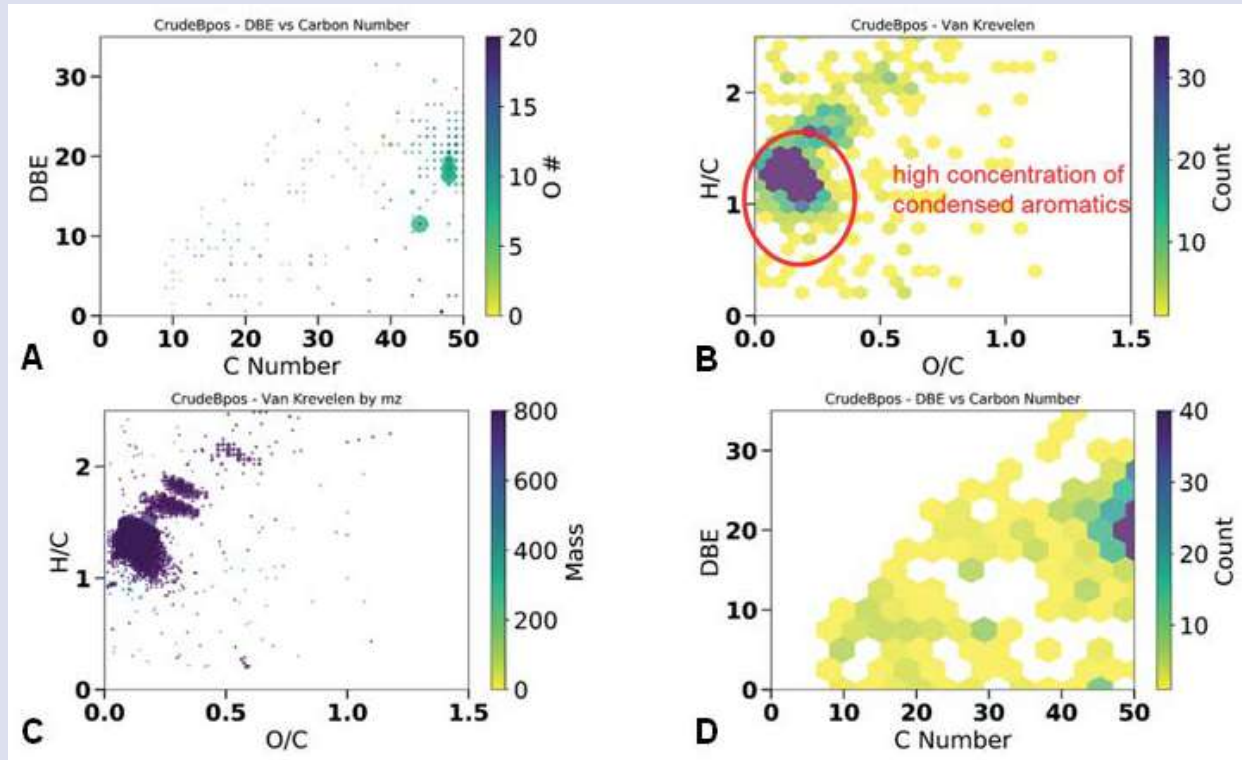

Figure 20: Van Krevelen plot for elemental data calculated from the ultrahigh-resolution mass spectrum (FTICR) for the sample named B1.

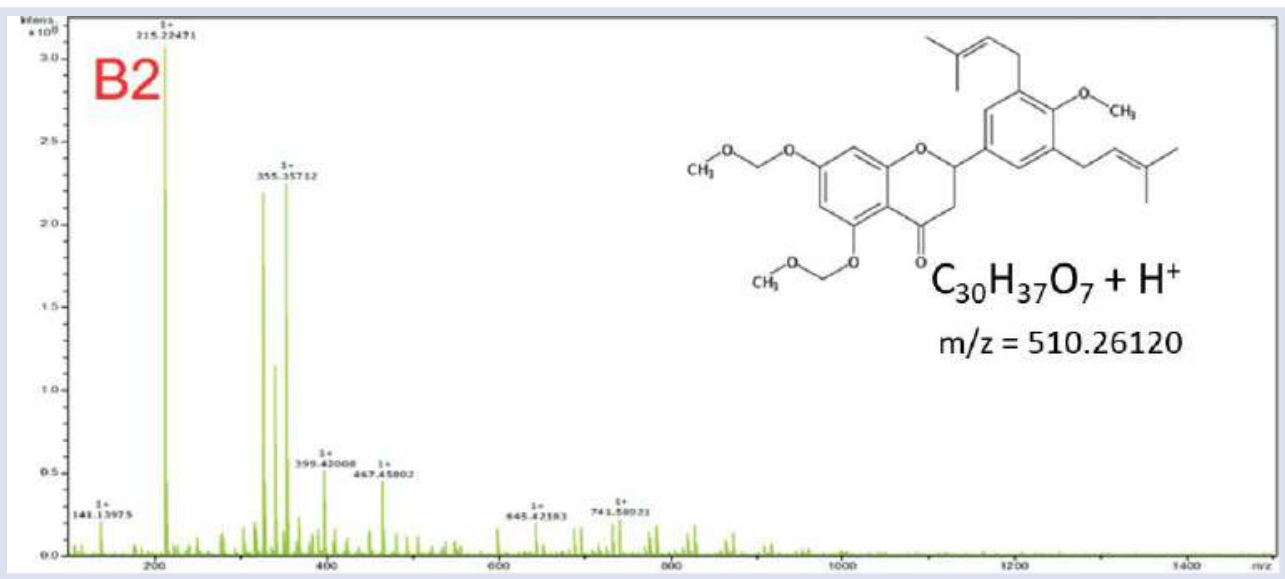

Figure 21: FTICR mass spectrum for the compound $\mathrm{C}_{30} \mathrm{H}_{38} \mathrm{O}_{7}$. From sample named B2. 2-(4-methoxy-3,5-bis(3-methylbut-2-en-1-yl)phenyl)-5,7bis(methoxymethoxy)chroman-4-one. 

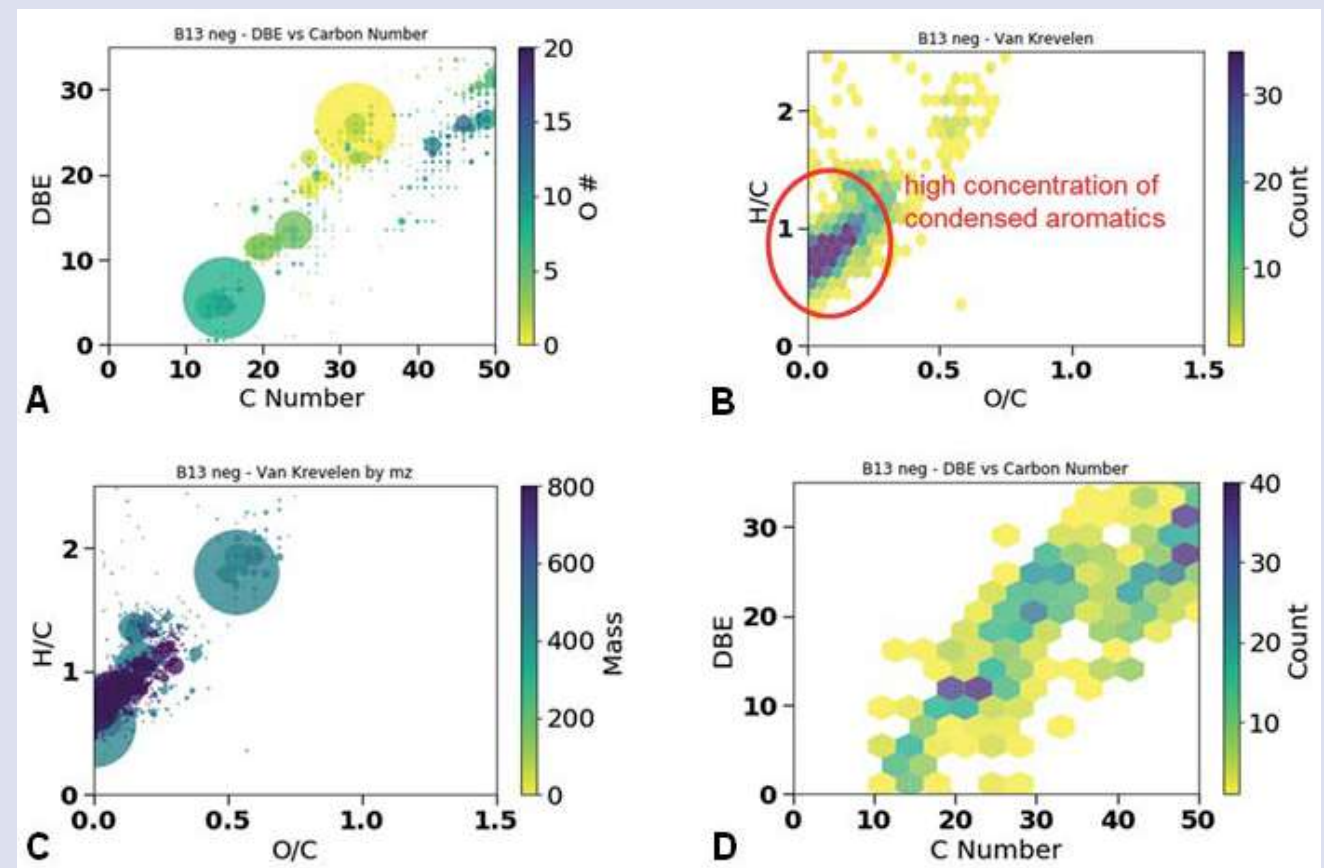

Figure 22: Van Krevelen plot for elemental data calculated from the ultrahigh resolution mass spectrum (FTICR) for the sample named B2.

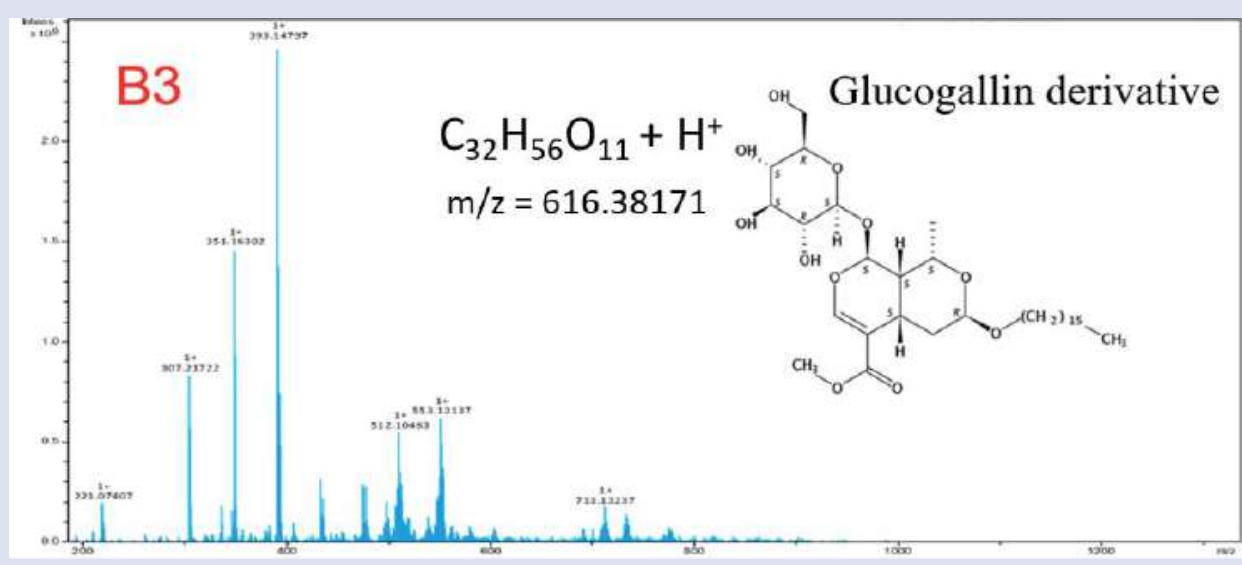

Figure 23: FTICR mass spectrum for the compound $\mathrm{C}_{32} \mathrm{H}_{56} \mathrm{O}_{11}$. From sample named $\mathrm{B} 3$ methyl $(3 \mathrm{R}, 4 \mathrm{aS}, 8 \mathrm{~S}, 8 \mathrm{aS})-3-($ hexadecyloxy)-8- $(((2 \mathrm{~S}, 3 \mathrm{R}, 4 \mathrm{~S}, 5 \mathrm{~S}, 6 \mathrm{R})-3,4,5-$ trihydroxy-6-(hydroxymethyl)tetrahydro-2H-pyran-2-yl)oxy)-4,4a,8,8a-tetrahydro-1H,3H-pyrano[3,4-c]pyran-5-carboxylate.

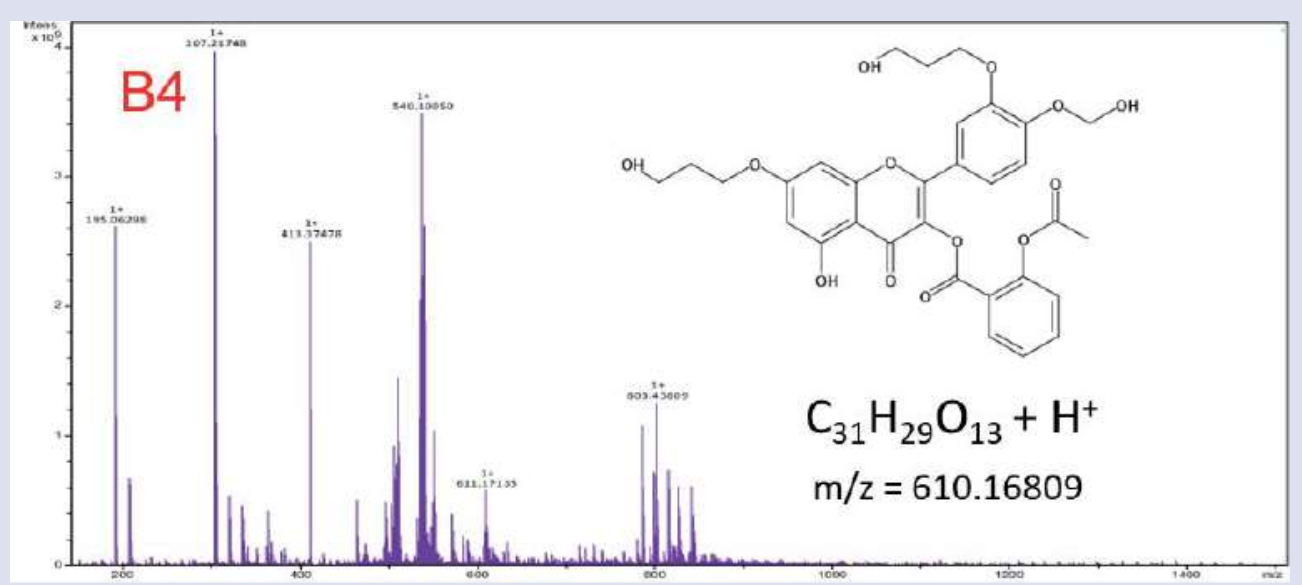

Figure 24: FTICR mass spectrum for the compound $\mathrm{C}_{31} \mathrm{H}_{30} \mathrm{O}_{13}$. :5-hydroxy-2-(4-(hydroxymethoxy)-3-(3-hydroxypropoxy)phenyl)-7-(3-hydroxypropoxy)-4oxo-4H-chromen-3-yl 2-acetoxybenzoate(quercetin derivative). 


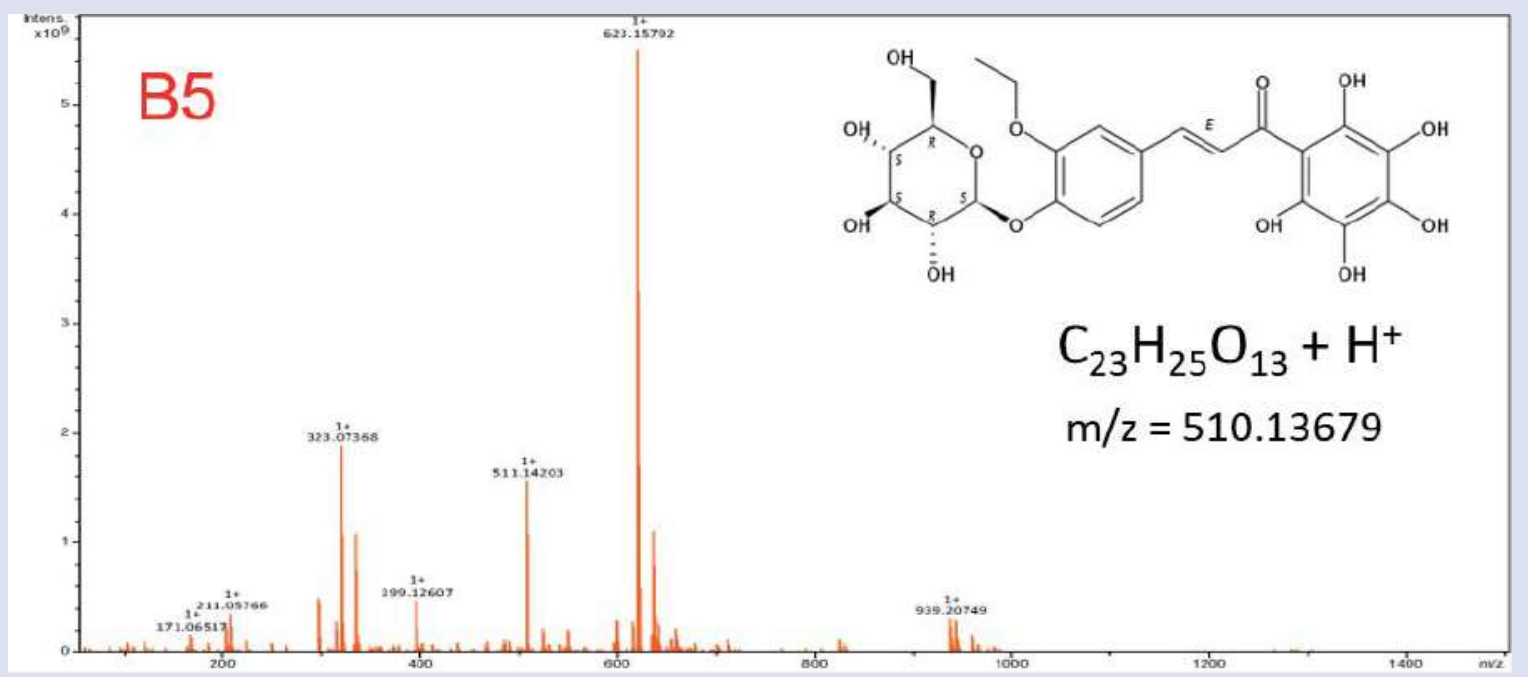

Figure 25: FTICR mass spectrum for the compound $\mathrm{C}_{23} \mathrm{H}_{26} \mathrm{O}_{13}$. From sample named $\mathrm{B} 5$. (E)-3-(3-ethoxy-4-(( $(2 \mathrm{~S}, 3 \mathrm{R}, 4 \mathrm{~S}, 5 \mathrm{~S}, 6 \mathrm{R})-3,4,5$-trihydroxy-6-(hydroxymethyl) tetrahydro-2H-pyran-2-yl)oxy)phenyl)-1-(2,3,4,5,6-pentahydroxyphenyl)prop-2-en-1-one. Ferulic acid derivative.

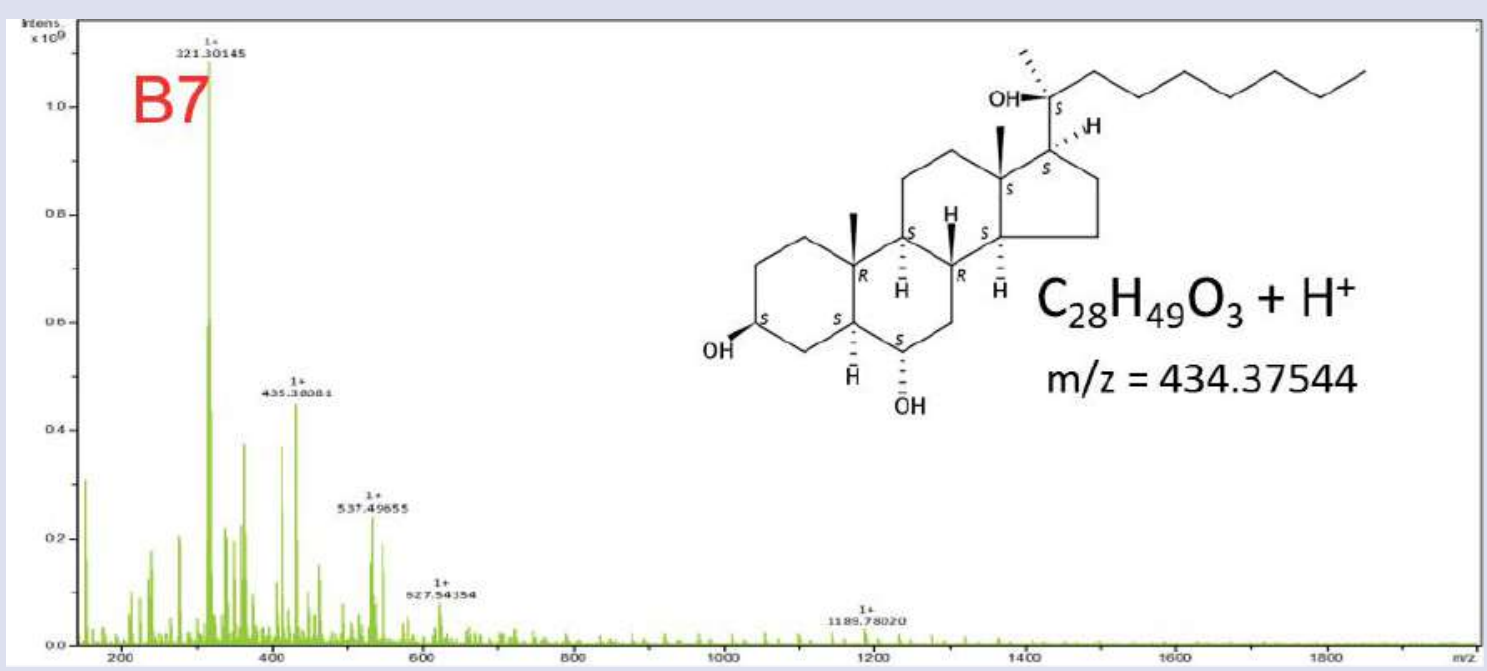

Figure 26: FTICR mass spectrum for the compound $\mathrm{C}_{19} \mathrm{H}_{18} \mathrm{O}_{7}$. From sample named B6. 2-(4-ethoxy-3-methoxyphenyl)-3,5-dihydroxy-7-methoxy-4Hchromen-4-one(Isorhamnetin derivative).

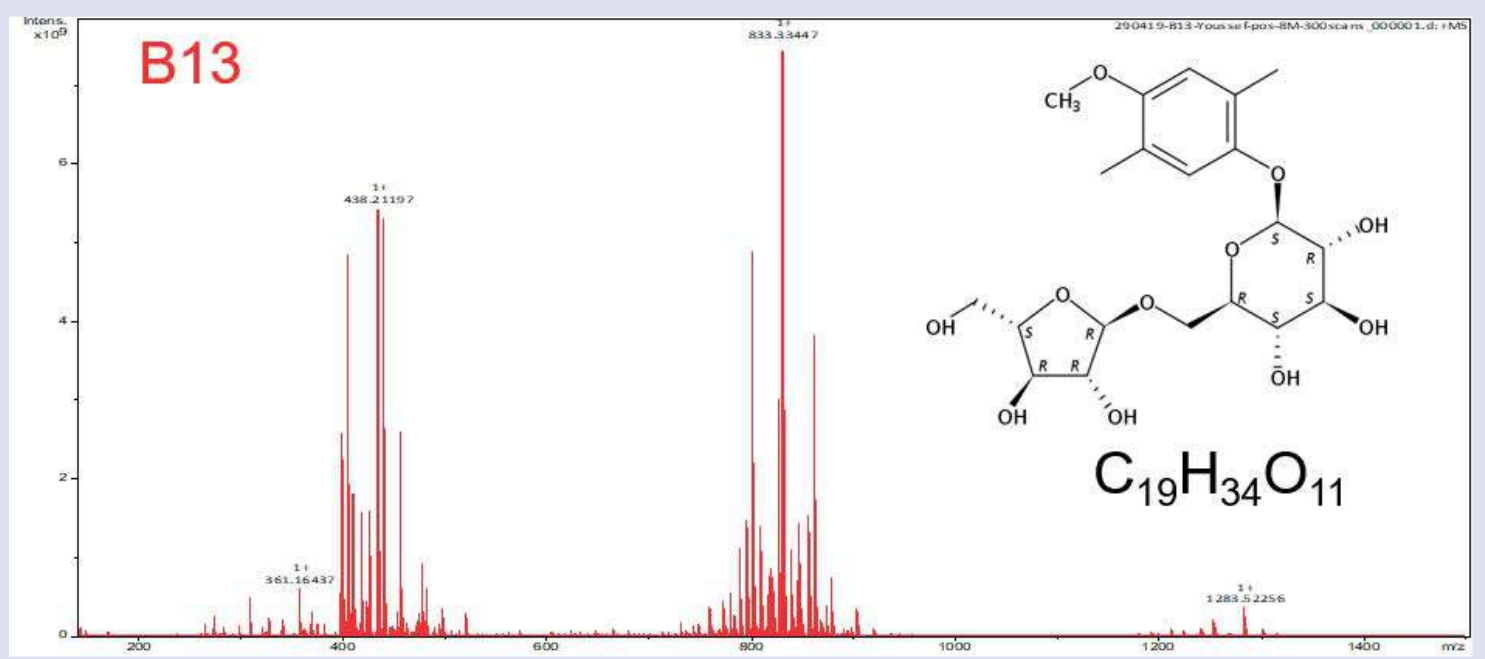

Figure 27: FTICR mass spectrum for the compound $\mathrm{C}_{28} \mathrm{H}_{50} \mathrm{O}_{3}$. From sample named $\mathrm{B} 7$. (3S, 5S,6S,8R,10R,13S,14S,17S)-17-((S)-2-hydroxynonan-2-yl)-10,13dimethylhexadecahydro-1H-cyclopenta[a]phenanthrene-3,6-diol(Nervosan derivative). 


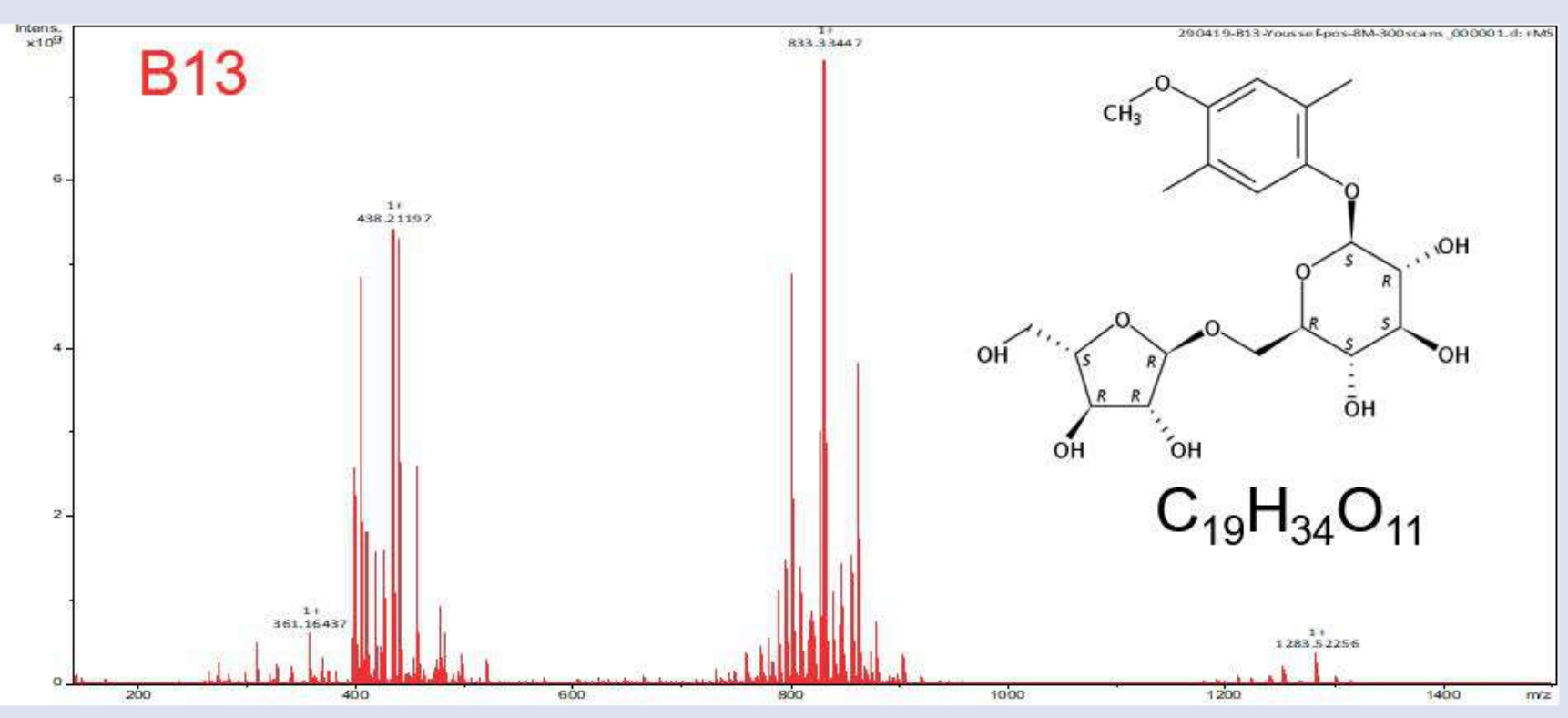

Figure 28: FTICR mass spectrum for the compound $\mathrm{C}_{19} \mathrm{H}_{34} \mathrm{O}_{11}$. From sample named B13phenolic acid (Tachioside derivative).

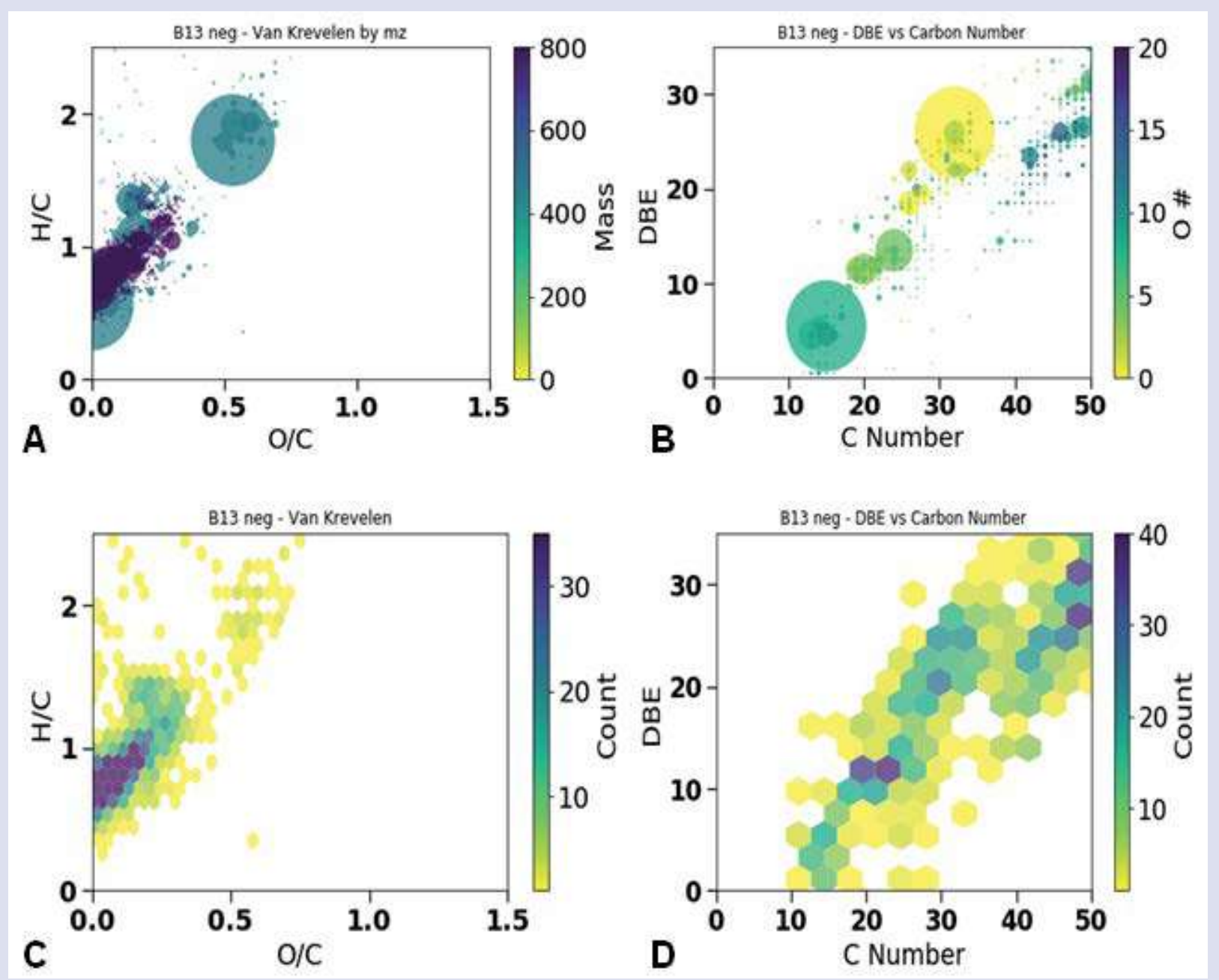

Figure 29: The Van Krevelen plot for elemental data calculated from the ultrahigh resolution mass spectrum (FTICR) for the sample named B13. 
fraction B1 (Figures 19 and 20). This class of compounds possesses anticancer activity as demonstrated in previous studies. ${ }^{15,16}$ Also, the flavonone compound sakuranetin derivative of molecular formula $\mathrm{C}_{30} \mathrm{H}_{38} \mathrm{O}_{7}$ detected in fraction $\mathrm{B} 2$ (Figures 21 and 22), it is well known that poly oxygenated unsaturated compounds, which are the properties that this compound has, have antioxidant effects that may stand behind its interesting anticancer property against $\mathrm{A} 549$ cell line with $\mathrm{IC}_{50}$ lower than $30 \mu \mathrm{g} / \mathrm{ml} .{ }^{6}$ This is consistent with the previous studies that reported the anticancer properties of Sakuranetin. ${ }^{17-19}$

Many other compounds, gallo tannin of molecular formula $\mathrm{C}_{32} \mathrm{H}_{56} \mathrm{O}_{11}$, quercetin derivative) $\mathrm{C}_{31} \mathrm{H}_{30} \mathrm{O}_{13}$, Dihydrochalcon derivative $\mathrm{C}_{23} \mathrm{H}_{26} \mathrm{O}_{13}$, 3-Hydroxyflavone isorhamnetin $\mathrm{C}_{19} \mathrm{H}_{18} \mathrm{O}_{7}$, nervosa derivative $\mathrm{C}_{28} \mathrm{H}_{50} \mathrm{O}_{3}$ and tachioside derivative $\mathrm{C}_{28} \mathrm{H}_{50} \mathrm{O}_{3}$ identified in fractions $\mathrm{B} 3$ (Figure 23), B4(Figure 24), B5(Figure 25), B6(Figure 26), B7(Figure 27) and B13 (Figures 28 and 29) respectively. In our previous study, fractions B5 and B13 showed cytotoxic activity. This activity might be due to the high percentage of hydroxyl groups in both compounds and being highly unsaturated. This finding is in agreement with previous publications that conform the anticancer activity of both dihydrochalcon and phenolic glycoside compounds. . $^{1520-22}$

\section{CONCLUSION}

The Fourier transform ion cyclotron resonance mass spectrometry (FTICR MS) instrumentation provides the best resolution performance and ultra-high-mass to charge ratio $(\mathrm{m} / \mathrm{z})$ accuracy of each analyte present in a complex mixture without the need for chromatographic separation. It also offers metabolite identification, quantification as well as accurate molecular weight information. The mass spectra of both Micromeria fruticosa and Teucrium polium showed high chemical complexities and reviled the presence of many classes of metabolites including lipids and flavonoids that possess antioxidant activities that might be responsible for the previously demonstrated significant anticancer activity against MCF7 and A549 cancer cell lines, More studies are needed to see whether a particular compound in each plant is responsible for the anticancer effect, or the synergistic effect of the compounds present in the plants lie behind it.

\section{ACKNOWLEDGEMENT}

Special thanks and appreciation to Professor Christian Rolando, MSAP , university of Lille, france, for his cooperation with us in the completion of this research

\section{REFERENCES}

1. Cowan MM. Plant products as antimicrobial agents. Clin.Microbiol Rev. 1999;12:564-582

2. Mohamad Hamwi MA. Genus Micromeria : A review article. BAU Journal- Health and well being. 2021.

3. AG Atanasov BWW. Discovery and resupply of pharmacologically active plant-derived natural products. Biotechnol. Adv. 2015;33:15821614.

4. M Al-Hamwi YBELO. Chemical Composition and Seasonal Variation of the Essential oil of Micromeria fruticosa. J. Nat. Prod. 2011;4:147.
5. Yazdi FTBB. Antimicrobial effect of the aqueous and ethanolic Teucrium polium L. extracts on gram positive and gram negative bacteria "in vitro. J Paramed Sc . 2013.

6. Mohammad Al- Hamwi MA. Anticancer Activity of Micromeria fruticos and Teucrium polium Growing in Lebanon. Pharmacognosy journal. 2021;13(1):103-109.

7. Daisaku Ohta SK. Application of Fourier-transform ion cyclotron resonance mass spectrometry to metabolic profiling and metabolite identification. Current Opinion in Biotechnology. 2010;21:35-44.

8. Wu ZR. Two- and threedimensional van Krevelen Diagrams: A graphical analysis complementary to the Kendrick mass plot for sorting elemental compositions of complex organic mixtures based on ultrahigh ultrahigh resolution mass measurements. Analytical Chemistry. 2004;76:2511-2516

9. Van Krevelen DW. Graphical-statistical method for the study of structure and reaction processes of coal. Fuel. 1950;24:269-284.

10. Kim SK. Graphical method for analysis of ultrahigh-resolution broadband mass spectra of natural organic matter, the Van Krevelen diagram. Analytical Chemistry. 2003;75(20):5336-5344.

11. Mann BF. Indexing permafrost soil organic matter degradation using high-resolution mass spectrometry. PLoS ONE. 2015.

12. Kew WB. Interactive van Krevelen diagrams-advanced visualisation of mass spectrometry data of complex mixtures. Rapid Communications in Mass Spectrometry. 2017;31:658-662

13. Stephen A Brockman EV. Van Krevelen diagram visualization of high resolution-mass spectrometry metabolomics data with OpenVanKrevelen. Metabolomics. 2018

14. Marisa Maia AE. Vitis vinifera 'Pinot noir' leaves as a source of bioactive nutraceutical compounds. Food Funct. 2019.

15. Melanie Kern ZT. Inhibitors of the epidermal growth factor receptor in apple juice extract. Molecular nutrition. 2005;49(4):page 3.

16. Quan Wang JE. Discovery of new chromen-4-one derivatives as telomerase inhibitors through regulating expression of dyskerin. Journal of enzyme inhibition and medicinal chemistry. 2018;33(1):1199-1211.

17. Stompor M. A Review on Sources and Pharmacological Aspects of Sakuranetin. Nutrients. 2020;12:513.

18. Jeong H, Lee J, Kim S, Yeo Y, So H, Wu H, et al. Hepatic Metabolism of Sakuranetin and Its Modulating Effects on Cytochrome P450s and UDP-Glucuronosyltransferases. Molecules. 2018;23:1542.

19. Michelle Nonato de Oliveira Melo AP. Phenolic compounds from Viscum album tinctures enhanced antitumor activity in Melanoma murine cancer cells. Saudi Pharmaceutical Journal. 2018;26(3): 311322.

20. Boccellino M, Quagliuolo L, D’Angelo SA. Apple Biophenols' Effects in Combination with Cisplatin on A549 Cells. Current Nutrition \& Food Science. 2021;17(1):111-120

21. Labony Khandokar MS. Ethnomedicinal uses, phytochemistry, pharmacological activities and toxicological profile of Glycosmis pentaphylla (Retz.) DC. Journal of Ethnopharmacology. 2021;278.

22. Mahmoud Zaki El-Readi SYA. Fallopia japonica: Bioactive Secondary Metabolites and Molecular Mode of Anticancer. Journal of Traditional Medicine \& Clinical Naturopathy. 2016;5(3). 


\section{GRAPHICAL ABSTRACT}
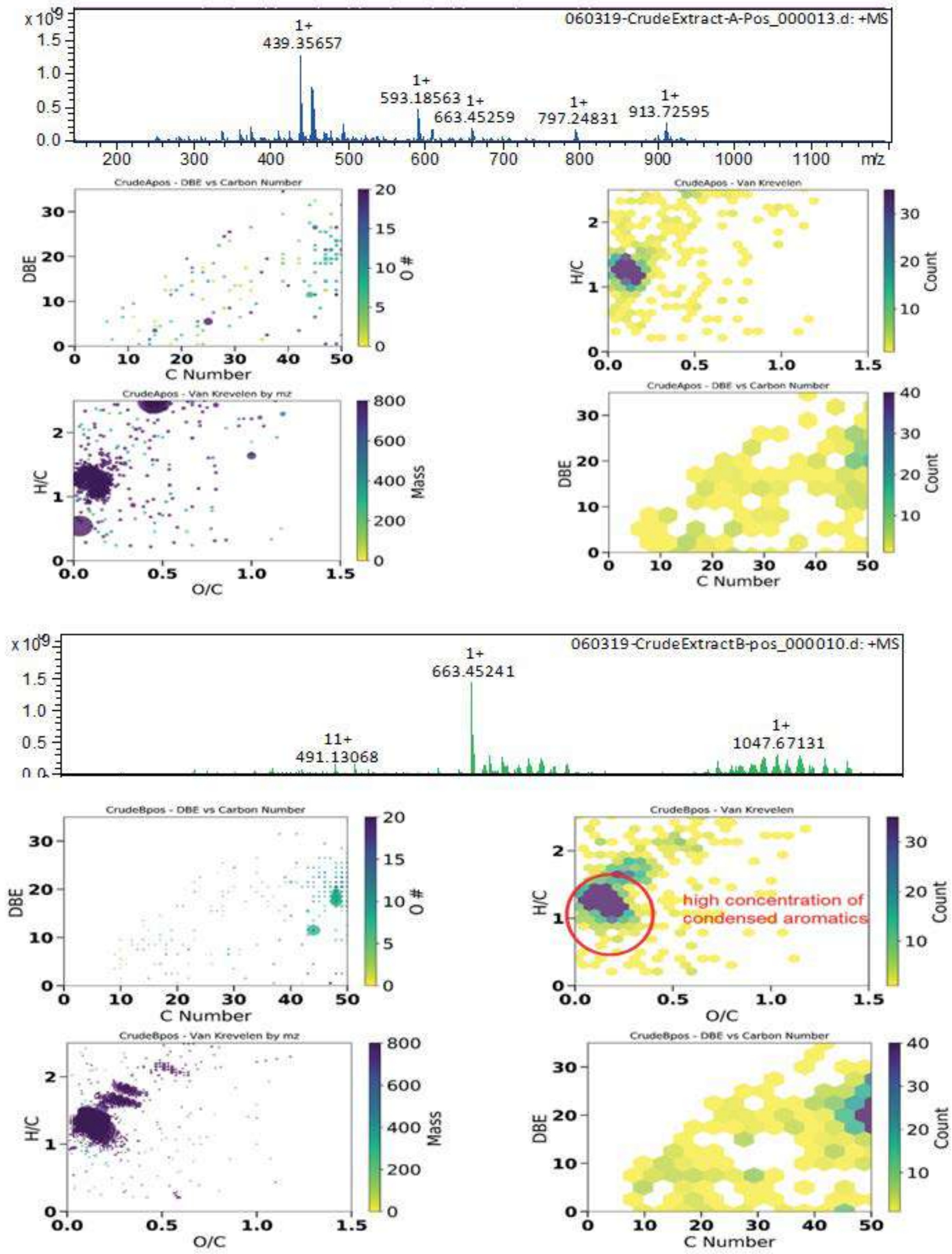


\section{ABOUT AUTHORS}
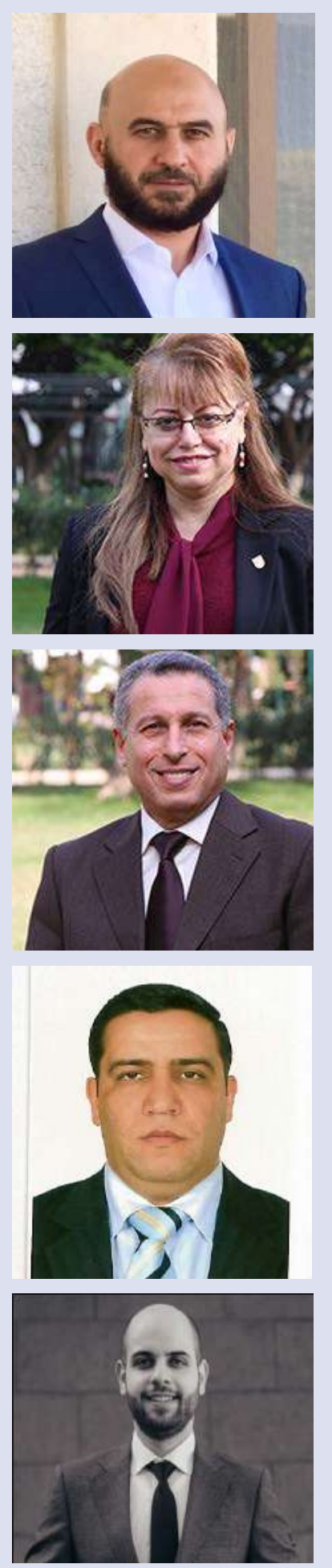

Mohamad Al- Hamwi, is a graduate of the Faculty of Pharmacy, Beirut Arab University, Master degree in Pharmacognosy and Medicinal plants, pharmaceutical sciences department, faculty of Pharmacy, BAU. Ph.D. candidate in pharmaceutical sciences department faculty of Pharmacy, BAU.

Prof Maha Aboul Ela. is a graduate of the Faculty of Pharmacy, University of Alexandria, Egypt. She has done her Ph.D. at the Department of Pharmacognosy, Faculty of Pharmacy, the University of Alexandria in collaboration with the Institute for Organic Chemistry, Technical University of Berlin, Germany. She has more than fifty publications in national and international journals and is the head of the pharmaceutical sciences department faculty of Pharmacy, Beirut Arab University.

Prof Abdalla El-Lakany, is a graduate of the Faculty of Pharmacy, Alexandria University. Based on academic excellence, he was granted a Ph.D. scholarship from the Faculty of Pharmacy, Alexandria University. He has published several research articles in the medicinal plant domain. Currently, he is the dean of the Faculty of Pharmacy at Beirut Arab University.

Professor Youssef BAKKOUR, HDR, PhD

Laboratory of Applied Chemistry, Lebanese University, Faculty of Sciences III, Tripoli, Lebanon.

Ziad Mahmoud, holder of a PhD in Analytical chemistry funded by the European infrastructure Horizon 2020 EU_FT-ICR_MS in the MSAP Unit, Miniaturization for Synthesis, Analysis and Proteomics (USR CNRS 3290) at the University of Lille, Faculty of Science and Technology under the supervision of Christian ROLANDO. The research work of the thesis focused on the chemical depolymerization of natural and synthetic polymers and their analysis by very high-resolution mass spectrometry on an FT-ICR MS (Fourrier Transform Ion cyclotron Resonance Mass Spectrometry) instrument with an involvement in the field of analysis of cultural heritage.

Cite this article: Al-Hamwi M, Ela M, El-lakany A, BAKKOUR Y, Mahmoud Z. FTICR/MS Analysis of Micromeria Fruticosa and Teucrium Polium Growing in Lebanon. Pharmacogn J. 2022;14(1): 112-127. 